\title{
Monocytes Differentiate to Immune Suppressive Precursors of Metastasis-Associated Macrophages in Mouse Models of Metastatic Breast Cancer
}

Takanori Kitamura ${ }^{1 *}$, Dahlia Doughty-Shenton ${ }^{2}$, Luca Cassetta ${ }^{1}$, Stamatina Fragkogianni', Demi Brownlie', Yu Kato ${ }^{3}$, Neil Carragher ${ }^{4}$ and Jeffrey W. Pollard ${ }^{1,3}$

${ }^{1}$ MRC Centre for Reproductive Health, Queen's Medical Research Institute, The University of Edinburgh, Edinburgh, United Kingdom, ${ }^{2}$ Edinburgh Phenotypic Assay Centre, Queen's Medical Research Institute, The University of Edinburgh, Edinburgh, United Kingdom, ${ }^{3}$ Department of Developmental and Molecular Biology, Albert Einstein College of Medicine, New York, NY, United States, ${ }^{4}$ Cancer Research UK Edinburgh Centre, MRC Institute of Genetics \& Molecular Medicine, The University of Edinburgh, Edinburgh, United Kingdom

OPEN ACCESS

Edited by: Anahid Jewett, University of California, Los Angeles, United States

Reviewed by: Viktor Umansky,

Deutsches Krebsforschungszentrum (DKFZ), Germany Amorette Barber, Longwood University, United States

${ }^{*}$ Correspondence: Takanori Kitamura tkitamur@exseed.ed.ac.uk

Specialty section: This article was submitted to Cancer Immunity and Immunotherapy, a section of the journal

Frontiers in Immunology

Received: 16 October 2017 Accepted: 26 December 2017

Published: 17 January 2018

Citation:

Kitamura T, Doughty-Shenton D,

Cassetta L, Fragkogianni S, Brownlie D, Kato Y, Carragher N and

Pollard JW (2018) Monocytes Differentiate to Immune Suppressive Precursors of Metastasis-Associated Macrophages in Mouse Models of Metastatic Breast Cancer.

Front. Immunol. 8:2004. doi: 10.3389/fimmu.2017.02004
Metastasis-associated macrophages (MAMs) play pivotal roles in breast cancer metastasis by promoting extravasation and survival of metastasizing cancer cells. In a metastatic breast cancer mouse model, we previously reported that circulating classical monocytes (C-MOs) preferentially migrated into the tumor-challenged lung where they differentiated into MAMs. However, the fate and characteristics of C-MOs in the metastatic site has not been defined. In this study, we identified that adoptively transferred C-MOs (F4/80 low CD11 $\mathrm{b}^{+} \mathrm{Ly}_{6 \mathrm{C}} \mathrm{C}^{+}$) differentiated into a distinct myeloid cell population that is characterized as $\mathrm{F} 4 / 80^{\text {high }} \mathrm{CD} 11 \mathrm{~b}^{\text {high }}$ Ly $6 \mathrm{C}^{\text {high }}$ and gives rise to MAMs ( $\mathrm{F} 4 / 80^{\text {low }} \mathrm{CD} 11 \mathrm{~b} \mathrm{~b}^{\text {high }} \mathrm{Ly} 6 \mathrm{C}^{\text {low }}$ ) within $18 \mathrm{~h}$ after migration into the metastatic lung. In mouse models of breast cancer, the CD11b high Ly6C high MAM precursor cells (MAMPCs) were commonly found in the metastatic lung, and their accumulation was increased during metastatic tumor growth. The morphology and gene expression profile of MAMPCs were distinct from C-MOs and had greater similarity to MAMs. For example MAMPCs expressed mature macrophage markers such as CD14, CD36, CD64, and CD206 at comparable levels with MAMs, suggesting that MAMPCs have committed to a macrophage lineage in the tumor microenvironment. MAMPCs also expressed higher levels of Arg1, Hmox1, and Stab1 than C-MOs to a comparable level to MAMs. Expression of these MAM-associated genes in MAMPCs was reduced by genetic deletion of colony-stimulating factor 1 receptor (CSF1R). On the other hand, transient CSF1R blockade did not reduce the number of MAMPCs in the metastatic site, suggesting that CSF1 signaling is active in MAMPCs but is not required for their accumulation. Functionally MAMPCs suppressed the cytotoxicity of activated $\mathrm{CD}^{+} \mathrm{T}$ cells in vitro in part through superoxide production. Overall, our results indicate that immediately following migration

Abbreviations: C-MO, classical monocyte; NC-MOs, non-classical monocytes; TAM, tumor-associated macrophage; MDSC, myeloid-derived suppressor cell; MAM, metastasis-associated macrophage; MAMPC, MAM progenitor cell; RMAC, resident macrophage; CSF1R, colony-stimulating factor 1 receptor; PyMT, polyoma middle T oncoprotein; ROS, reactive oxygen species; SOD, superoxide dismutase. 
into the metastatic tumors C-MOs differentiate into immunosuppressive cells that have characteristics of monocytic myeloid-derived suppressor cell phenotype and might be targeted to enhance efficacy of immunotherapy for metastatic breast cancer.

Keywords: breast cancer, metastasis, macrophage, myeloid-derived suppressor cell, immune suppression, $\mathrm{CD}^{+} \mathrm{T}^{\mathrm{T}}$ cell

\section{INTRODUCTION}

Breast cancer is the most common cancer in women worldwide, accounting for $23 \%$ of the total new cancer cases (1). The mortality rate of breast cancer has been decreasing due to the development of early detection techniques and improvement in treatment (1). However, breast cancer cells frequently metastasize to the bone and lung, which dramatically reduces 5-year survival of breast cancer patients to less than 25\% (2). Indeed, data show that survival of metastatic breast cancer patients has not significantly improved over the past 30 years (3). This depressing statistic indicates the requirement of novel approaches that efficiently block metastatic tumor development.

Attractive targets for improvements in therapy are tumorinfiltrating immune cells such as regulatory T cells, tumor-associated neutrophils, myeloid-derived suppressor cells (MDSCs), and tumor-associated macrophages (TAMs), as these cells play pivotal roles in the establishment of metastatic tumors (4). In particular, TAMs have been shown to be critical promoters of metastatic breast cancer development following early experiments that showed marked suppression of tumor progression and metastasis by genetic macrophage depletion in a mouse model of breast cancer in which mammary tumors are caused by the mammary epithelial restricted polyoma middle $\mathrm{T}$ oncoprotein (PyMT) expression (5). In addition, many studies have correlated poor prognosis of breast cancer patients with high infiltration of TAMs into the tumor (6). Data from mouse models of metastatic breast cancer have also defined mechanisms of this metastasis promotion indicating that TAMs support tumor cell invasion and intravasation at the primary sites (7), enhance angiogenesis (8), transmit survival signals to the metastasizing tumor cells (9), and promote extravasation and persistent growth of tumor cells at the metastatic site (10). In addition, there is preliminary evidence that TAMs are involved in immunosuppression. For example, TAMs express high levels of programmed death ligand 1 (PD-L1), a ligand for immune-checkpoint receptor that restricts $\mathrm{CD}^{+} \mathrm{T}$ cell activities $(11,12)$, and the targeting of TAMs improves efficacy of the check-point inhibitors in a pancreatic ductal carcinoma model in mice (13). It is also reported that TAMs suppress $\mathrm{CD}^{+} \mathrm{T}$ cell-mediated anti-tumor immunity in the mammary tumor of PyMT mice under treatment with chemotherapy (14). Therefore, TAMs represent important potential therapeutic target to treat metastatic breast cancer (4).

One of the most extensively explored strategies to target TAMs is the inhibition of colony-stimulating factor 1 receptor (CSF1R) (12). Antagonists or blocking antibodies against CSF1R suppress the accumulation of TAMs as well as changing their phenotype, enhance $\mathrm{CD}^{+} \mathrm{T}$ cell-mediated antitumor immune responses, and prevent disease progression or primary tumor growth in mouse models of glioblastoma, pancreatic, colon, and breast cancer (13-16). These data based on genetically engineered mouse models of the primary tumor suggest that TAM intervention by
CSF1R inhibition is an attractive strategy to block environmental support for malignant tumor development and to improve therapeutic efficacy of $\mathrm{CD}^{+} \mathrm{T}$ cell-based immunotherapy.

For therapeutic TAM intervention aimed at blocking the metastatic tumor expansion, a better understanding of macrophages in the metastatic sites is important since macrophages change their phenotypes in response to environmental factors and these might be different between the primary and metastatic tumors (17). In mouse models of metastatic breast cancer, there are at least two distinct macrophage populations characterized as $\mathrm{F} 4 / 80^{+} \mathrm{CD} 11 \mathrm{~b}^{\text {low }} \mathrm{CD} 11 \mathrm{c}^{\text {high }}$ and $\mathrm{F} 4 / 80^{+} \mathrm{CD} 11 \mathrm{~b}^{\text {high }} \mathrm{CD} 11 \mathrm{c}^{\text {low }}$ in the lung with metastatic tumors (10). The CD11 $c^{\text {high }}$ macrophage population consists of alveolar macrophages that also exist in the normal lung $(18,19)$. In contrast, the CD11 bigh macrophages markedly accumulate in the tumor-challenged lung but are significantly less in the normal lung (10). In an experimental metastasis model using Met-1 mouse breast cancer cells on a FVB genetic background, depletion of these CD11 $\mathrm{b}^{\text {high }}$ metastasisassociated macrophages (MAMs) but not CD11 $c^{\text {high }}$ resident macrophages (RMACs) reduces the number and size of metastatic foci (10). In this model, a subset of monocytes characterized as $\mathrm{CD}_{11 \mathrm{~b}^{+} \mathrm{Ly} 6 \mathrm{C}^{+}}$[classical monocytes (C-MOs)] preferentially migrates to the tumor-challenged lung via a chemokine receptor CCR2, and inhibition of their recruitment results in the reduction of the number of MAMs (CD11 $\left.b^{\text {high }} \mathrm{Ly} 6 \mathrm{C}^{\text {low }}\right)$ and metastatic tumor load in the lung (20). In another experimental metastasis model using E0771-LG mouse breast cancer cells on a C57BL/6 background, adoptively transferred CD $11 b^{+}$Ly $6 \mathrm{C}^{+} \mathrm{C}-\mathrm{MO}$ differentiate to a CD $11 b^{\text {high }}$ Ly $6 C^{\text {low }}$ population within $42 \mathrm{~h}$ posttransfer (21). Although a minor macrophage population in the normal lung called interstitial macrophages is also characterized as $\mathrm{CD}_{11} \mathrm{~b}^{+} \mathrm{CD} 11 \mathrm{c}^{\text {low }}(18,19)$, these cells are not rapidly replenished by C-MOs (22) and their accumulation by bacterial CpG DNA does not require CCR2 (23). Collectively, these data indicate that the circulating C-MOs differentiate into MAMs at the metastatic sites, which promotes the establishment of metastatic tumors. Therefore, C-MOs in the differentiation process at the metastatic site can be a novel therapeutic target for the treatment of metastatic breast cancer, and thus it is important to understand their dynamics and characteristics after infiltrating the metastatic tumors.

In this article, we have identified that circulating C-MOs differentiate into a distinct myeloid cell population characterized as $\mathrm{CD} 11 \mathrm{~b}^{\text {high }} \mathrm{Ly} 6 \mathrm{C}^{\text {high }}$ in the metastatic lung where they further differentiate into MAMs. The CD11 $\mathrm{b}^{\text {high }} \mathrm{Ly} 6 \mathrm{C}^{\text {high }} \mathrm{MAM}$ precursor cells (MAMPCs) expressed mature macrophage markers, and their gene expression profile was similar with that of MAMs but distinct from C-MOs. We also found that accumulation of the $\mathrm{CD}_{11} \mathrm{~b}^{\text {high }}$ Ly6 $\mathrm{C}^{\text {high }}$ cells was increased when micro-metastasis started to outgrow, and was not suppressed by blockade of CSF1R. We further identified that the MAMPCs suppressed cytotoxic 
ability of $\mathrm{CD}^{+} \mathrm{T}$ cells through reactive oxygen species (ROS)mediated but checkpoint ligands-independent mechanism. These results indicate that $\mathrm{C}$-MOs recruited to the metastatic tumors produce immune suppressive precursor MAMs that may not be targeted by CSF1R antagonists or checkpoint inhibitors.

\section{MATERIALS AND METHODS}

\section{Mice}

MMTV-PyMT mice (24) on the C57BL/6 background were obtained from Dr. Sandra J. Gendler (Mayo Clinic College of Medicine) who had backcrossed PyMT mice established by Dr. William J Muller (McGill University, Montreal, Canada) originally on the FVB background. To analyze the lung with metastatic tumors, we used female PyMT mice on the C57BL/6 background at 20-25 weeks of age. Csf1r-EGFP (MacGreen) (25) mice on the C57BL/6 background were obtained from Dr. David Hume (University of Edinburgh). Conditional CSF1R knockout (Csf1r cKO) mice (i.e., rtTA:tetO-Cre:Csf1r $r^{\mathrm{F} / \mathrm{F}}$ ) were obtained by crossing the B6.Cg-Csf1 $r^{\mathrm{tm} 1 \mathrm{Jw} / \mathrm{J}}\left(C s f 1 r^{\mathrm{F} / \mathrm{F}}\right)$ mice (26) with ROSA-rtTA and tetO-Cre mice (Jackson lab) (21). Animals were housed and bred under standard conditions of care. All procedures involving mice were conducted in accordance with licensed permission under the UK Animal Scientific Procedures Act (1986) (Home Office license number PPL 70/8065) and Institutional Animal Care \& Use Committee of the Albert Einstein College of Medicine (20120304).

\section{Tumor Cell Lines}

Met-1 mouse mammary tumor cells derived from the MMTVPyMT tumor in FVB mice (27) and highly metastatic derivative of E0771 mouse mammary adenocarcinoma cells derived from a medullary cancer in C57BL/6 mice (E0771-LG) (21) were cultured in DMEM supplemented with $10 \% \mathrm{v} / \mathrm{v}$ FBS, $100 \mathrm{U} / \mathrm{mL}$ penicillin, and $100 \mu \mathrm{g} / \mathrm{mL}$ streptomycin. E0771-LG cells were manipulated to express firefly luciferase (E0771-LG:Fl) or nuclear localized red fluorescent protein (mKate) (E0771-LG:NLR) to detect the cells by in vivo bioluminescence imaging or in vitro fluorescence microscopy, respectively. We have confirmed that all cells were negative for mycoplasma.

\section{Breast Cancer Metastasis Models in Mice}

As experimental models of metastatic breast cancer, we injected $1 \times 10^{6}$ of E0771-LG or Met- 1 cells into the tail vein of C57BL/6 or FVB mice (7-week-old female), respectively. At 7-14 days (E0771-LG) or 21 days (Met-1) posttumor cell injection, we euthanized the mice and isolated the blood and lung to prepare samples for flow cytometry or H\&E staining.

\section{In Vivo Bioluminescence Imaging}

We intraperitoneally injected D-luciferin in PBS (GoldBio, $1.5 \mathrm{mg} / 100 \mu \mathrm{L} / 20 \mathrm{~g}$ mouse) into anesthetized E0771-LG:Fl tumorbearing mice. Bioluminescence from the luciferase-expressing tumor cells was imaged using Photon Imager Optima (Biospace Lab), and photon counts (photon/second $/ \mathrm{cm}^{2} / \mathrm{sr}$ ) in the lung area were quantified by image analysis software (M3 Vision, Biospace Lab).

\section{Adoptive Transfer of Monocytes}

We isolated C-MOs from the bone marrow of MacGreen mice by Monocyte Isolation Kits (Miltenyi). $5 \times 10^{5}$ of the $\mathrm{GFP}^{+} \mathrm{C}-\mathrm{MOs}$ were transferred into $\mathrm{C} 57 \mathrm{BL} / 6$ mice that have received intravenous injection of E0771-LG:Fl cells. Pulmonary tumor burdens in the recipient mice were determined by bioluminescence imaging 1 day before monocyte transfer (10 days after tumor injection). Eighteen, 42, 66, or $90 \mathrm{~h}$ after the C-MO transfer, we euthanized the animals and isolated the blood and lung for flow cytometry.

\section{Flow Cytometry and Sorting}

Single-cell suspensions from perfused lungs were prepared via enzymatic digestion using the Lung Dissociation Kit (Miltenyi) and following filtration through a $40 \mu \mathrm{m}$ cell strainer. Red blood cells in the lung digestions and blood samples were removed using RBC lysis buffer (Biolegend). The samples were blocked with antimouse CD16/CD32 antibody (BD bioscience), and stained with DAPI and fluorescent antibodies to following antigens; CD45 (30-F11), F4/80 (BM8), CD11b (M1/70), Ly6C (HK1.4), CD115 (AFS98), Ly6G (1A8), CD11c (N418), CD14 (Sa14-2), CD36 (HM36), CD64 (X54-5/7.1), CD206 (C068C2), CCR5 (HM-CCR5), PD-L1 (10F.9G2), CD80 (16-10A1), CD86(GL-1) all from Biolegend, and PD-L2 (122) from eBioscience. Flow cytometry was performed using LSRII cytometer (BD Biosciences) and analyzed using Flowjo software (TreeStar). In some experiments, the stained C-MOs $\left(\mathrm{CD} 115^{+} \mathrm{Ly}_{6 \mathrm{G}} \mathrm{CD}^{\mathrm{C}} 1 \mathrm{~b}^{+} \mathrm{Ly} 6 \mathrm{C}^{\text {high }}\right)$ in the blood or bone marrow, MAMPCs (F4/80 ${ }^{+} \mathrm{Ly} 6 \mathrm{G}^{-} \mathrm{CD} 11 \mathrm{~b}^{\text {high }} \mathrm{Ly} 6 \mathrm{C}^{\text {high }}$ ),

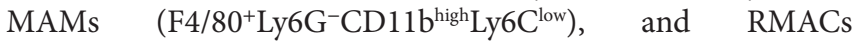

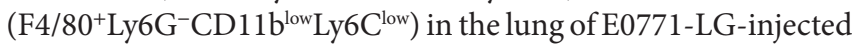
mice were sorted using FACS Artia II (BD Biosciences).

\section{Microarray Analysis}

We sorted C-MOs from the bone marrow and MAMPCs and MAMs from the lung with E0771-LG metastatic tumors $(N=3$ per group) as described above. We extracted RNA from these cells by RNeasy Micro Kit (Qiagen) and used this for hybridization on Affymetrix MoGene 2.0 ST chip. Datasets were annotated and normalized using the robust multichip average algorithm ( $r m a$ ) from the GenePattern platform. All statistical calculations were performed in $\mathrm{R}$ programming language (version 3.2.3). The dataset was analyzed using the oligo package from Bioconductor. Multiple probes were collapsed to single gene using the average expression (avereps function). Using the Limma package, a linear model was fitted for the identification of differentially expressed genes. Genes with FDR $\leq 0.05$ and $\log _{2} \mathrm{FC} \geq+1.0$ (upregulated) or $\log _{2} \mathrm{FC} \leq-1.0$ (downregulated) are considered to be differentially expressed. Venn diagrams were drawn using the differentially expressed genes between the populations. Heat maps were drawn using the gplots package on the differentially expressed genes between MAMPC and C-MO populations. A clustering method was set to complete and distance measure to Pearson correlation.

\section{Real-time Quantitative RT-PCR Analysis}

We isolated total RNA from C-MOs, MAMPCs, MAMs, and RMACs as described above, and performed reverse transcription using oligo(dT)18 primers with SuperScript III (Invitrogen). 
Real-time quantitative PCR was performed using SYBR master mix (Invitrogen) on the Applied Biosystems 7500 Real-Time PCR System (Applied Biosystems) by the following program: preheating at $95^{\circ} \mathrm{C}$ for $10 \mathrm{~min}, 40$ cycles of amplification consisting of $15 \mathrm{~s}$ denaturing at $95^{\circ} \mathrm{C}, 30 \mathrm{~s}$ annealing at $61^{\circ} \mathrm{C}$, and $20 \mathrm{~s}$ extension at $72^{\circ} \mathrm{C}$. Relative expression of target genes was determined according to $\Delta \Delta C_{t}$ with normalization to Gapdh expression. Primers used for PCR were: $A d m, 5^{\prime}$-CACCCTGATGTTATTGGGTTCA-3' and 5' ${ }^{\prime}$-TTAGCGCCCACTTATTCCACT-3' ; Arg1, 5' -CTCCAAGCC AAAGTCCTTAGAG-3' and $5^{\prime}$-AGGAGCTGTCATTAGGGAC ATC-3'; Cd163, 5'-GGTGGACACAGAATGGTTCTTC-3' and 5'-CCAGGAGCGTTAGTGACAGC-3'; Hmox1, 5' -AAGCCGA GAATGCTGAGTTCA-3' and 5'-GCCGTGTAGATATGGTACA AGGA-3'; Mrc1, 5'-CTCTGTTCAGCTATTGGACGC-3' and 5'-CGGAATTTCTGGGATTCAGCTTC-3'; Stab1, 5'-GGCAG ACGGTACGGTCTAAAC-3' and $5^{\prime}$-AGCGGCAGTCCAGAA GTATCT-3'; Gapdh, 5' -AGAACATCATCCCTGCATCC-3' and 5'-CACATTGGGGGTAGGAACAC-3'.

\section{Blockade of CSF1 Receptor}

For genetic depletion of CSF1 receptor, we gave doxycycline (SIGMA, $20 \mathrm{mg} / \mathrm{mL}$ ) in drinking water with $5 \% \mathrm{w} / \mathrm{v}$ sucrose to the rtTA:tetO-Cre:Csf1r $r^{\mathrm{F} / \mathrm{F}}$ (Csf1r cKO) mice from 7 days after tumor injection to the endpoint. For pharmacological CSF1R inhibition, we gave BLZ945 (Selleckchem, $4 \mathrm{mg} / 20 \mathrm{~g}$ mouse, oral gavage) from 7 days after tumor injection to the endpoint.

\section{In Vitro CD8 ${ }^{+} \mathrm{T}$ Cell Cytotoxicity Assay}

We isolated $\mathrm{CD}^{+} \mathrm{T}$ cells from the spleen of $\mathrm{C} 57 \mathrm{BL} / 6$ mice by EasySep Mouse $\mathrm{CD}^{+} \mathrm{T}$ Cell Isolation Kit (Stemcell technologies). $1 \times 10^{5}$ of $\mathrm{CD}^{+} \mathrm{T}$ cells were cultured with or without $1 \times 10^{5}$ of MAMPCs, MAMs, or RMACs from the E0771-LG tumor-bearing lung in enriched DMEM $(20 \% \mathrm{v} / \mathrm{v}$ FBS, $2 \mathrm{mM}$ L-glutamine, $1 \% \mathrm{v} / \mathrm{v}$ non-essential amino acid, $1 \mathrm{mM}$ sodium pyruvate, $50 \mathrm{nM}$ 2-mercaptoethanol, $100 \mathrm{U} /$ $\mathrm{mL}$ penicillin, $100 \mu \mathrm{g} / \mathrm{mL}$ streptomycin) containing $80 \mathrm{U} /$ $\mathrm{mL}$ IL-2, $2 \mu \mathrm{g} / \mathrm{mL}$ anti-CD3e (145-2C11, Biolegend), and $5 \mu \mathrm{g} / \mathrm{mL}$ anti-CD28 (37.51, Biolegend). In some experiment, we added $\mathrm{N}^{\mathrm{G}}$-Methyl-L-arginine acetate salt (L-NMMA, SIGMA, $500 \mu \mathrm{M}$ ), $\quad \mathrm{N}^{\omega}$-hydroxy-nor-arginine (nor-NOHA, Cambridge Bioscience, $500 \mu \mathrm{M}$ ), catalase (SIGMA, 1,000 U/ $\mathrm{mL}$ ), and superoxide dismutase (SOD, SIGMA, $200 \mathrm{U} / \mathrm{mL}$ ) into the culture. After 4 days, $\mathrm{CD}^{+} \mathrm{T}$ cells (non-adherent) were collected and resuspended in enriched DMEM including $1,000 \mathrm{U} / \mathrm{mL}$ IL-2. The activated $\mathrm{CD}^{+} \mathrm{T}$ cells (effector) were then cocultured with $1 \times 10^{3}$ of E0771-LG:NLR cells (target) at different effector/target ratio in the presence of fluorogenic caspase-3 substrate (NucView488, Biotium) in 96-well plates coated with basement membrane extract (Geltrex, Gibco). The cultured cells were imaged by IncuCyte Zoom Live-Cell Analysis System (Essen Bioscience) for $48 \mathrm{~h}$, and number of apoptotic cancer cells (red/green double positive) were counted using IncuCyte S3 software.

\section{Statistical Analysis}

Sample size was determined for power based on a relative SD from our previous studies. All samples were collected independently and analyzed by at least two independent experiments. Data were analyzed by Student's $t$-test and are expressed as mean \pm SEM. $P$-values $<0.05$ were considered significant.

\section{RESULTS}

\section{C-MO Differentiate into a Distinct Population That Gives Rise to MAMs in the Metastatic Site}

To understand the fate of C-MOs in the metastatic sites, we utilized MacGreen mice on a C57/BL6 background in which myeloid cells including monocytes and macrophages express green fluorescent protein (GFP) under the regulation of the CSF1R promoter (25). We transferred purified C-MOs from MacGreen mice into the C57BL/6 mice that have developed metastatic tumors in the lung following injection of E0771-LG mouse breast cancer cells that colonize the lung and form metastatic tumors. We tracked the fate of the $\mathrm{GFP}^{+}$cells in the blood and lung at 18, 42, 66, and $90 \mathrm{~h}$ postinjection (Figure 1A). Since it was impractical to collect significant numbers of monocytes from peripheral blood, we isolated the C-MOs from the bone marrow that were characterized as $\mathrm{CD} 11 \mathrm{~b}^{+} \mathrm{Ly}_{6 \mathrm{C}^{+} \mathrm{CD}} 115^{+}$but did not express markers for neutrophils (Ly6G) or hematopoietic stem/progenitor cells (c-Kit and Sca-1) (Figure S1 in Supplementary Material). By $18 \mathrm{~h}$ posttransfer, almost all $\mathrm{GFP}^{+}$ cells in the blood remained in a $\mathrm{CD} 11 \mathrm{~b}^{+} \mathrm{Ly} 6 \mathrm{C}^{+}$population that is characteristic for the C-MOs (Figures 1B,C). In contrast, $\mathrm{GFP}^{+}$ cells in the metastatic lung expressed higher levels of CD11b and Ly6C and a majority of them were found as a CD $11 b^{\text {high }}$ Ly $6 C^{\text {high }}$ population distinct from the $\mathrm{GFP}^{+}$cells and the intrinsic C-MOs in blood (Figures 1B,C). By $42 \mathrm{~h}$ after transfer, the $\mathrm{GFP}^{+}$cells in the metastatic lung still expressed higher level of CD11b than C-MOs. However, more than half of cells had reduced Ly6C expression and thereby shifted to a CD $11 b^{\text {high }}$ Ly $6 C^{\text {low }}$ population that resembles the phenotype of MAMs (10). The ratio of the CD $11 b^{\text {high }}$ Ly6 $6 \mathrm{C}^{\text {low }}$ population increased by $90 \mathrm{~h}$ after transfer, and that of $C D 11 b^{\text {high }}$ Ly $6 C^{\text {high }}$ population concomitantly reduced (Figures 1B,C), indicating that $\mathrm{CD} 11 \mathrm{~b}^{\text {high }} \mathrm{Ly} 6 \mathrm{C}^{\text {high }} \mathrm{GFP}^{+}$cells are progenitors of MAMs. Interestingly around $15 \%$ of $\mathrm{GFP}^{+}$ cells in the lung after $90 \mathrm{~h}$ were outside the CD11b ${ }^{\text {high }}$ Ly6 $6 \mathrm{C}^{\text {low }}$ gate probably due to the reduction in their $\mathrm{CD} 11 \mathrm{~b}$ expression (Figure 1B). In our model, the transferred C-MOs in the blood became non-classical monocytes (NC-MOs) character-

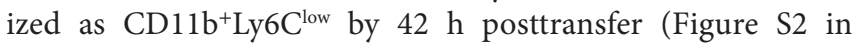
Supplementary Material) consistent with previous studies (28). However, these cells were distinct from the $\mathrm{GFP}^{+}$cells in the lung that were characterized as $\mathrm{CD} 11 \mathrm{~b}^{\text {high }} \mathrm{Ly} 6 \mathrm{C}^{\text {low. }}$. The $\mathrm{GFP}^{+}$cells in the metastatic lung expressed higher levels of $\mathrm{F} 4 / 80$ and major histocompatibility complex II (MHC-II) than $\mathrm{GFP}^{+}$cells in the blood and intrinsic C-MOs (Figure 1D), suggesting their commitment to a macrophage lineage. Given their low expression of CD11c and Ly6G, these cells were distinct from RMACs, dendritic cells, or neutrophils (Figure 1D). As shown in Figure 1E, the $\mathrm{CD} 11 \mathrm{~b}^{\text {high }} \mathrm{Ly} 6 \mathrm{C}^{\text {high }}$ population was also found in the intrinsic $\mathrm{F} 4 / 80^{+}$cells that accumulated in metastatic lungs, indicating that their presence is not an artifact of adoptive transfer. Although 

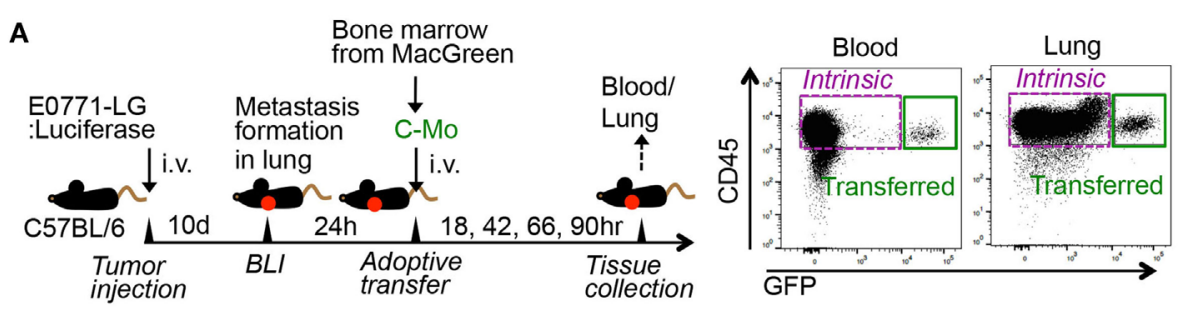

B

Transferred GFP+ cells

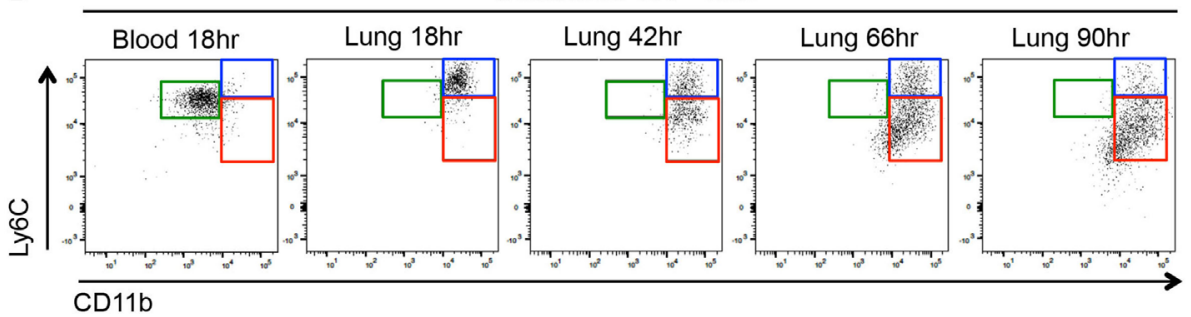

C
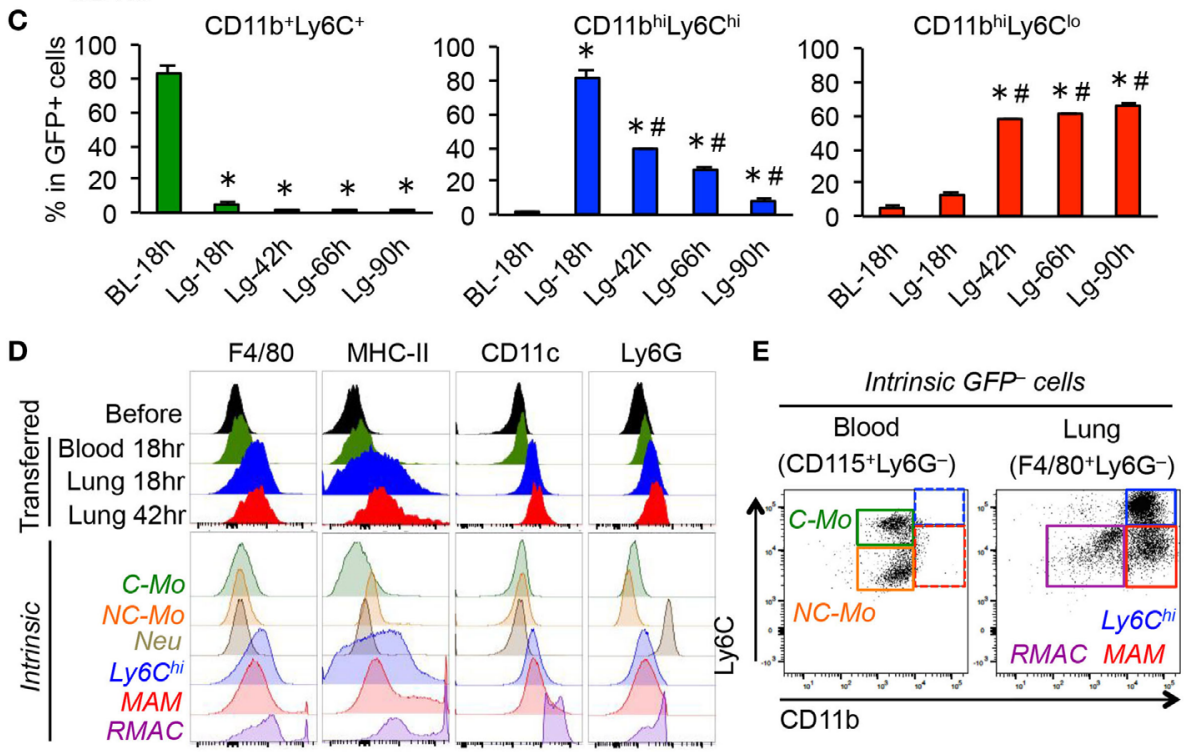

FIGURE 1 | Adoptively transferred classical monocytes (C-MOs) differentiate into a distinct myeloid population that gives rise to metastasis-associated macrophages (MAMs) in the metastatic site. (A) A scheme of the monocyte tracking experiment (left) and representative dot plots showing the transferred (GFP+) and intrinsic (GFP-) cells in the blood and lung of the tumor-bearing monocyte-transferred mouse (right). (B) Representative dot plots showing expression of CD11b and Ly6C in the transferred GFP+ cells in the blood and lung of tumor-bearing mice after the indicated time posttransfer $(n=3 /$ group, two independent experiments). Three typical populations characterized as CD11b+Ly6C+ (green), CD11 b high Ly6C high (blue), and CD11 b high Ly6C ${ }^{\text {low }}$ (red) were shown. (C) Percentage is shown of $\mathrm{CD} 11 \mathrm{~b}+\mathrm{Ly}_{6} \mathrm{C}^{+}, \mathrm{CD} 11 \mathrm{~b}^{\text {high }}$ Ly6C high, and CD11b high Ly6C $\mathrm{C}^{\text {low }}$ populations in GFP+ cells ( $n=3 /$ group, two independent experiments). Data are mean $\pm \mathrm{SEM}$, ${ }^{*} P<0.01$ vs. blood $18 \mathrm{~h}$ (BL-18 h), ${ }^{\#} P<0.01$ vs. lung $18 \mathrm{~h}$ (Lg-18 h). (D) Representative histograms showing expression of indicated markers in the transferred $\mathrm{GFP}^{+}$cells in the blood and lung as well as GFP+ cells before transfer (before). As a control, expressions of markers in intrinsic cells from the tumor-bearing mouse are shown in the bottom. C-MO, non-classical monocytes (NC-MO), and neutrophils (Neu) were identified in blood, and CD11 b ${ }^{\text {high }}$ Ly6C ${ }^{\text {high }}$ Cells (Ly6Chi), MAM, and resident macrophages (RMAC) were detected in the metastatic lung. Data are representative of two independent experiments with three mice per group.

(E) Representative dot plots showing expression of CD11b and Ly6C in the intrinsic CD115+Ly6G- cells in the blood and F4/80+Ly6G- cells in the lung from the E0771-LG-injected C57BL/6 mice used in (B) ( $n=3$, two independent experiments). Three typical populations characterized as C-MO (green), NC-MO (orange), CD11 b high Ly6C high (blue), MAM (red), and RMAC (purple) were shown.

the $\mathrm{CD} 11 \mathrm{~b}^{\text {high }} \mathrm{Ly} 6 \mathrm{C}^{\text {high }}$ cells might be considered as monocytes, their expression of CD11b, Ly6C, F4/80, and MHC-II clearly distinguish them from circulating C-MOs (Figures 1B,D,E). Collectively, these results indicate that circulating C-MOs differentiate to MAMPCs characterized as $\mathrm{CD} 11 \mathrm{~b}^{\text {high }} \mathrm{Ly} 6 \mathrm{C}^{\text {high }}$ once they migrate to the metastatic site. Hereafter we call the CD11b ${ }^{\text {high }}$ Ly6C ${ }^{\text {high }}$ cells MAMPCs.

\section{MAMPC Accumulation in Metastatic Sites Is Increased during Metastatic Tumor Outgrowth}

To investigate whether the MAMPCs accumulate in spontaneous pulmonary metastases, we analyzed lung metastatic lesions in PyMT mice on C57BL/6 background. Consistent with our 
results using transferred cells (Figure 1B), we found that $\mathrm{F} 4 / 80^{+}$ cells in the spontaneous metastatic lung but not in the normal lung included a CD11 $b^{\text {high }}$ Ly6 $\mathrm{C}^{\text {high }}$ population (i.e., MAMPCs) that is distinct from MAMs (CD11b ${ }^{\text {high }} \mathrm{Ly} 6 \mathrm{C}^{\text {low }}$ ) and RMACs $\left(\mathrm{CD} 11 \mathrm{~b}^{\text {low }} \mathrm{Ly} 6 \mathrm{C}^{\text {low }}\right.$ ) (Figure 2A). The relative numbers of MAMPCs as well as MAMs were significantly higher in the metastatic lung compared with the normal lung (Figure 2B), whereas the ratio of RMACs was relatively low due to the recruitment of myeloid cells to the tumors. We also analyzed another metastatic breast cancer model, i.e., FVB mice intravenously injected with Met-1 mouse mammary tumor cells (27). Consistent with the other two models, we found a significant increase in the numbers of MAMPCs and MAMs in the lung with metastatic tumors compared with normal lung (Figures 2C,D), suggesting that accumulation of the $\mathrm{CD} 11 \mathrm{~b}^{\text {high }}$ Ly6 $\mathrm{C}^{\text {high }}$ MAMPCs in the metastatic site is not a model-dependent artifact. To understand the timing of MAMPC accumulation in the metastatic lung, we utilized the experimental metastasis model using E0771-LG cells in which intravenously transplanted cancer cells reproducibly develop micro-metastases in the lung by day 7 that subsequently grow into macro-metastatic lesions by day 14 (Figure 2E). We found that the ratio of cells in the MAMPC gate increased by day 7 and further increased by day 14 (Figure 2F). Similarly, accumulation of cells in the MAM gate but not RMACs was increased when metastatic tumors grow in the lung (Figure 2F). Taken together, these results indicate that accumulation of MAMPCs is associated with the metastatic tumor outgrowth in mouse models of metastatic breast cancer.

\section{Morphology and Gene Profile of MAMPCs Are Distinct from C-MOs but Similar to MAMs}

To further characterize MAMPCs, we analyzed the morphology of cells isolated by gating C-MOs, MAMPCs, and MAMs from
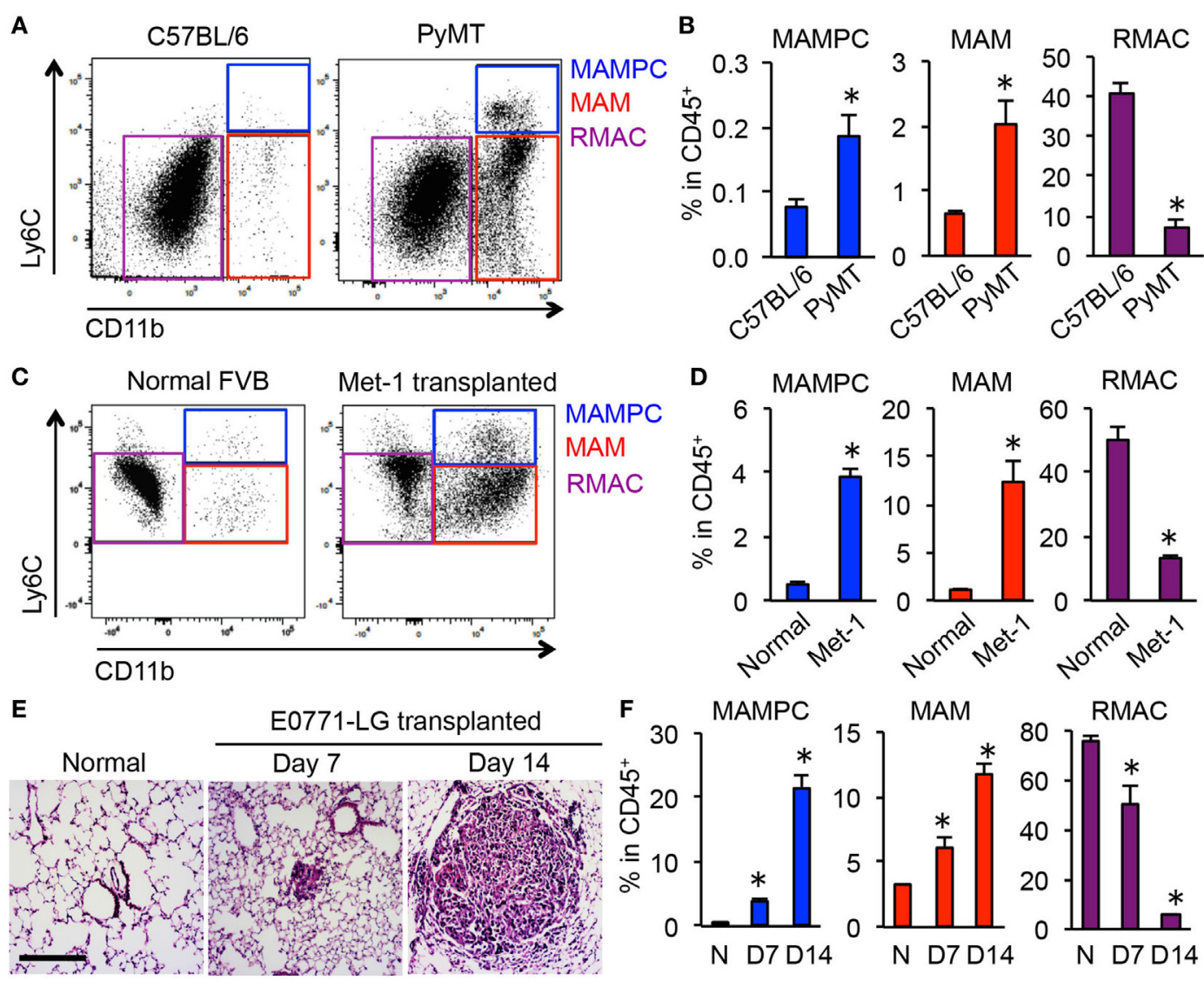

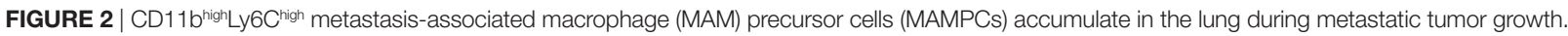
(A) Representative dot plots of the lung of normal C57BL/6 and BL6;PyMT mice that have established metastatic tumors ( $n=3$, three independent experiments). Cells were first gated as CD45+F4/80+, and then MAMPCs (blue), MAMs (red), and resident macrophages (RMACs) (purple) were defined as CD11 b ${ }^{\text {high }} \mathrm{Ly} 6 \mathrm{C}^{\text {high }}$, CD11 bhigh Ly6Clow, and CD11b-Ly6Clow, respectively. (B) Relative numbers of MAMPCs, MAMs, and RMACs in the lung of C57BL/6 and metastasis-bearing PyMT mice ( $n=3$, three independent experiments). Data are mean \pm SEM, ${ }^{\star} P<0.05$. (C) Representative dot plots of the lung from normal and metastasis-bearing FVB mice at 21 days after intravenous injection of Met-1 mouse mammary tumor cells ( $n=3$, two independent experiments). Cells were gated as described in (A). (D) Relative numbers of MAMPCs, MAMs, and RMACs in the normal and Met-1 tumor-bearing (Met-1) lung at 21 days after tumor injection ( $n=3$, two independent experiments). Data are mean \pm SEM, ${ }^{*} P<0.05$. (E) Representative H\&E-stained lung sections from normal C57BL/6 mice and from those transplanted with E0771-LG cells 7 or 14 days before isolation of the lung. Scale bar; $200 \mu \mathrm{m}$. (F) Relative numbers of cells with the phenotypes of MAMPCs, MAMs, and RMACs in the lung of normal $(\mathrm{N}, n=4)$ and tumor-injected mice at days 7 and 14 post-E0771-LG injection mice $\left(n=3\right.$, two independent experiments). Data are mean \pm SEM, ${ }^{\star} P<0.05$. 


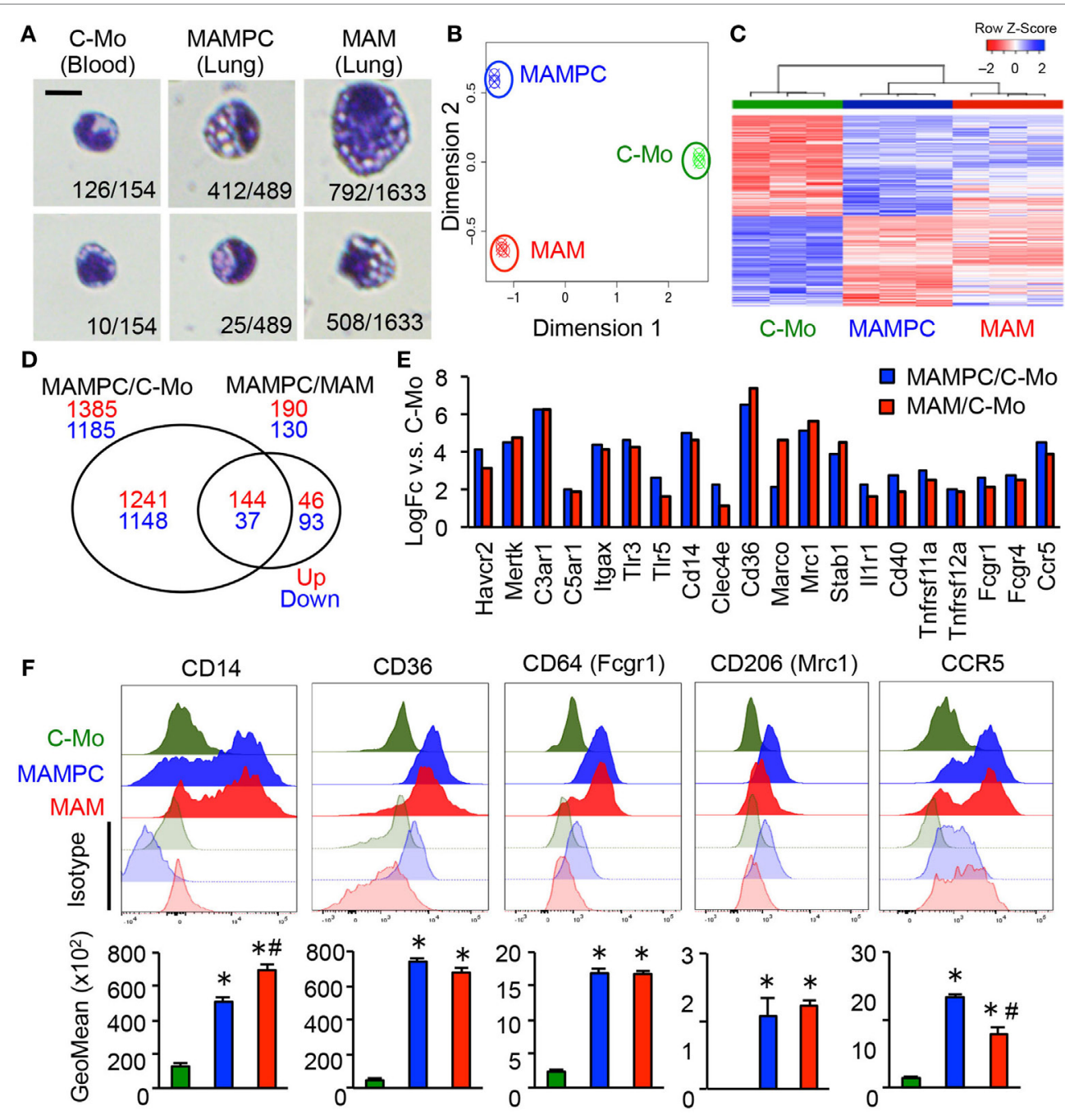

FIGURE 3 | The metastasis-associated macrophage (MAM) precursor cells (MAMPCs) are morphologically and transcriptionally distinguishable from classical monocytes (C-MOs) and MAMs. (A) Representative morphology of C-MOs in the blood, and MAMPCs and MAMs in the lung of mice with E0771-LG metastatic tumors. Scale bar; $10 \mu \mathrm{m}$. The number of cells with the indicated morphology in the total counted cells is shown. (B) Unsupervised multidimensional scaling (MDS) plot of the normalized gene expression of RNA isolated from C-MOs, MAMPCs, and MAMs ( $n=3 /$ group). C-MOs were isolated from the bone marrow and MAMPCs and MAMs were isolated from the lung of mice bearing E0771-LG metastatic tumors. (C) Unsupervised hierarchical clustering of differentially expressed genes (FDR < 0.05) between MAMPC and C-MO populations. Columns indicate samples, rows indicate genes, and color intensity represents the Z-scoretransformed RNA expression values. Samples are clustered using complete linkage and Pearson correlation. (D) Venn diagram of the commonly regulated genes in MAMPCs compared with C-MOs or MAMs ( $\log _{2} F C$ more or less than $-1 / 1$, FDR $=<0.05$ ). (E) Genes encoding macrophage receptors that were upregulated in MAMPCs (blue) and MAMs (red) compared with IMs (logFC $>1, P<0.01)$. Genes were clustered according to their ligands, i.e., phosphatidylserine receptors (Havcr2, Mertk), complement receptors (C3ar1, C5ar1, ItgaX), Toll-like receptors and coreceptor (TIr3, TIr5, Cd14), C-type lectin (Clec4e), scavenger receptors (Cd36, Marco, Mrc1, Stab1), cytokine and chemokine receptors (IIr1, Cd40, Tnfsf11a, Tnfsf12a, Ccr5), and Fc receptors (Fcgr1, Fcgr4). Data on expression values are presented as mean \pm SEM. Note that the scale is exponential. (F) Representative histogram (top) and mean fluorescent intensity (bottom) of indicated proteins in C-MOs, MAMPCs, and MAMs ( $n=3$, two independent experiments). Blood (for C-MOs) and lung digestion (for MAMPCs and MAMs) were prepared from E0771-LG-injected C57BL/6 mice at 14 days posttumor injection and stained with antibodies for indicated markers or isotype lgG. Data are mean \pm SEM, ${ }^{*} P<0.01$ vs. C-MO, ${ }^{*} P<0.01$ vs. MAMPC.

the blood and lung of mice that have developed metastatic tumors by E0771-LG cells but have not received monocyte transfer. Most of the cells sorted by C-MO gate from the blood (126/154, 88\%) showed the typical morphology of monocytes (Figure 3A), i.e., bi-lobate nucleus and a cytoplasm devoid of granules (29). In contrast, the majority of the cells sorted by MAMPC gate from the metastatic lung $(412 / 489,84 \%)$ were distinguishable from
C-MOs by their larger cellular size $(6.7 \pm 0.05$ and $5.7 \pm 0.05 \mu \mathrm{m}$ in diameter for MAMPCs and C-MOs, respectively, $P<0.01)$ and a vacuolated cytoplasm (Figure 3A), whereas a minority of them showed a similar morphology with C-MOs (25/489, 5\%). Cells with cytoplasmic vacuoles were rarely found in the C-MO gate $(10 / 154,6 \%)$. In contrast, the majority of cells sorted by the MAM gate from the metastatic lung $(1,300 / 1,633,80 \%)$ had vacuoles in 
their cytoplasm. More than half of these vacuolated cells in MAM gate $(792 / 1,300,61 \%)$ were larger than MAMPCs $(8.7 \pm 0.05 \mu \mathrm{m}$ and $6.7 \pm 0.05$ in diameter for MAMs and MAMPCs, respectively, $P<0.01)$, whereas $39 \%(508 / 1,300)$ of cells were comparable in size $(6.2 \pm 0.05 \mu \mathrm{m})$ with MAMPCs (Figure 3A). These results suggest that MAMPCs are in an intermediate stage of differentiation from C-MOs to MAMs.

To identify similarity and difference between C-MOs, MAMPCs, and MAMs we compared gene expression profiles of these cells by microarray analysis. To obtain sufficient cells, C-MOs were isolated from the bone marrow. Unsupervised multidimensional scaling plot of all expressed genes showed distinct clusters of the three populations, suggesting that MAMPCs are a distinct cell type from C-MOs and MAMs (Figure 3B). On the other hand, differential expression analysis and hierarchical clustering showed that there were fewer differentially expressed genes between MAMPCs and MAMs compared to C-MOs (Figures 3C,D; Table S1 in Supplementary Material), suggesting the phenotypic similarity between MAMPCs and MAMs. The array data also indicated that MAMPCs and MAMs both expressed higher levels of key macrophage receptor genes (30) than C-MOs, which included genes encoding phosphatidylserine receptors (Havcr2, Mertk), complement receptors (C3ar1, C5ar1, ItgaX), Toll-like receptors and coreceptor (Tlr3, Tlr5, Cd14), C-type lectin (Clec4e), scavenger receptors (Cd36, Marco, Mrc1, Stab1), cytokine and chemokine receptors (Ilr1, Cd40, Tnfsf11a, Tnfsf12a, Ccr5), and Fc receptors (Fcgr1, Fcgr4) (Figure 3E). To validate the array data, we determined expression of these receptors by flow cytometry in C-MOs from the blood and MAMPCs and MAMs from the lungs of mice with metastatic tumors. We confirmed that MAMPCs and MAMs in the metastatic lung expressed significantly higher levels of CD14, CD36, CD64 (Fcgr1), CD206 (Mrc1) and CCR5 proteins compared with circulating $\mathrm{C}-\mathrm{MOs}$ in the tumor-bearing mice (Figure 3F). Expression of other receptors could not be analyzed due to the lack of reliable antibodies for flow cytometry. Taken together, these results indicate that MAMPCs are morphologically and phenotypically closer to MAMs rather C-MOs from which they derive.

\section{CSF1R Is Required for MAMPCs to Express TAM Signature Genes but Not to Accumulate in the Metastatic Site}

We next investigated whether MAMPCs require CSF1R signal that is known to be essential for the recruitment, differentiation, and survival of TAMs $(5,31,32)$. Our microarray data suggest that CSF1R signaling is active in MAMPCs and the cells express transcripts for CSF1R regulated genes at higher abundance than C-MOs, as mRNA levels of direct effectors of CSF1R signaling pathway (i.e., Ets2 and Egr2) were fourfold higher in MAMPCs compared with C-MOs (Figure 4A). A recent study using a glioblastoma mouse model has identified ten signature genes whose expression in TAMs is regulated by CSF1R signaling, i.e., Adm1, Arg1, Cd163, Cdh1, F13a1, Hmox1, Il1r2, Mrc1, Serpinb2, and Stab1 (15). We thus examined our gene list to determine whether these CSF1R dependent TAM signature genes were upregulated in MAMPCs, and found that levels of six genes (Adm1, Arg1, Cd163, Cdh1, Hmox1, Il1r2, Mrc1, and Stab1) were significantly higher $(\operatorname{logFC}>1.5, P<0.01)$ in MAMPCs than C-MOs (Figure 4A). Expression of these genes were also higher in MAMs than C-MOs. To confirm the array data, we compared mRNA levels of the six genes in C-MOs from the blood, MAMPCs, MAMs, and RMACs from the lung of mice with metastatic tumors. We found that expression of Arg1, Hmox1, Mrc1, and Stab1 was significantly higher in MAMPCs than C-MOs and RMACs (Figure 4B). To investigate the involvement of CSF1R signaling in the expression of these genes, we utilized Csf1r conditional knockout (Csf1r-cKO) mice in which Csf1r gene is deleted by doxycycline treatment (21). The Csf1r-cKO and control C57BL/6 mice that have developed micro-metastases in the lung (Figure 2E) were treated with doxycycline for 1 week. These treatments significantly reduced CSF1R expression in C-MOs (the precursors of MAMPCs) in the Csf1r-cKO but not wild-type mice (Figure 4C). We found that almost all of the TAM signature genes except for Mrc1 were downregulated in MAMPCs as well as MAMs by loss of CSF1R (Figure 4D), suggesting that CSF1R signaling is necessary for MAMPCs to express MAM signature genes when they are differentiated from circulating C-MOs.

We then asked whether the activation of CSF1R is required for the accumulation of MAMPCs in the metastatic site. As we expected, 1-week of treatment with doxycycline after micrometastasis formation significantly suppressed the accumulation of MAMs. However, the treatment did not reduce the number of MAMPCs or C-MOs (Figure 4E). Likewise, 1-week treatment of tumor-injected C57BL/6 mice with a specific CSF1R antagonist BLZ945 reduced the number of MAMs in the lung without affecting the number of MAMPCs and C-MOs (Figure 4F). These results suggest that CSF1 signal is required for MAMPCs to acquire MAM-like phenotype whereas other signals might be involved in the full development of MAMPCs from C-MOs and their subsequent survival. Since MAMPCs continuously produce MAMs, a single treatment with CSF1R antagonist might not be sufficient in time or degree of inhibition to prevent metastatic tumor outgrowth. Consistently, the short-term blockade of CSF1R after micrometastasis formation showed negligible effects on the metastatic tumor expansion (Figures 4G,H), although long-term genetic MAM depletion through loss of Csf1 substantially inhibits metastasis (10).

\section{MAMPCs Suppress Cytotoxicity of $\mathrm{CD}^{+}{ }^{+} \mathrm{T}$ Cells In Vitro}

The phenotype of MAMPCs with CD11b $b^{\text {high }}$ Ly6C ${ }^{\text {high }}$ Ly6G $6 \mathrm{G}^{-}$resembles that of a subpopulation of MDSCs called monocytic MDSCs (M-MDSCs) (33). Since MDSCs and TAMs have been reported to suppress antitumor immune reaction in primary tumor models $(11,34,35)$, we hypothesized that MAMPCs and MAMs in the metastatic site also possess immune suppressive phenotypes and thus performed an in vitro $\mathrm{CD}^{+} \mathrm{T}$ cell cytotoxicity assay. In this assay, we cultured E0771-LG cancer cells expressing red fluorescent protein (target) with splenic $\mathrm{CD}^{+} \mathrm{T}$ cells that were preincubated with anti-CD3/CD28 antibodies (effector), and detected tumor cell apoptosis indicated by green fluorescence from a 


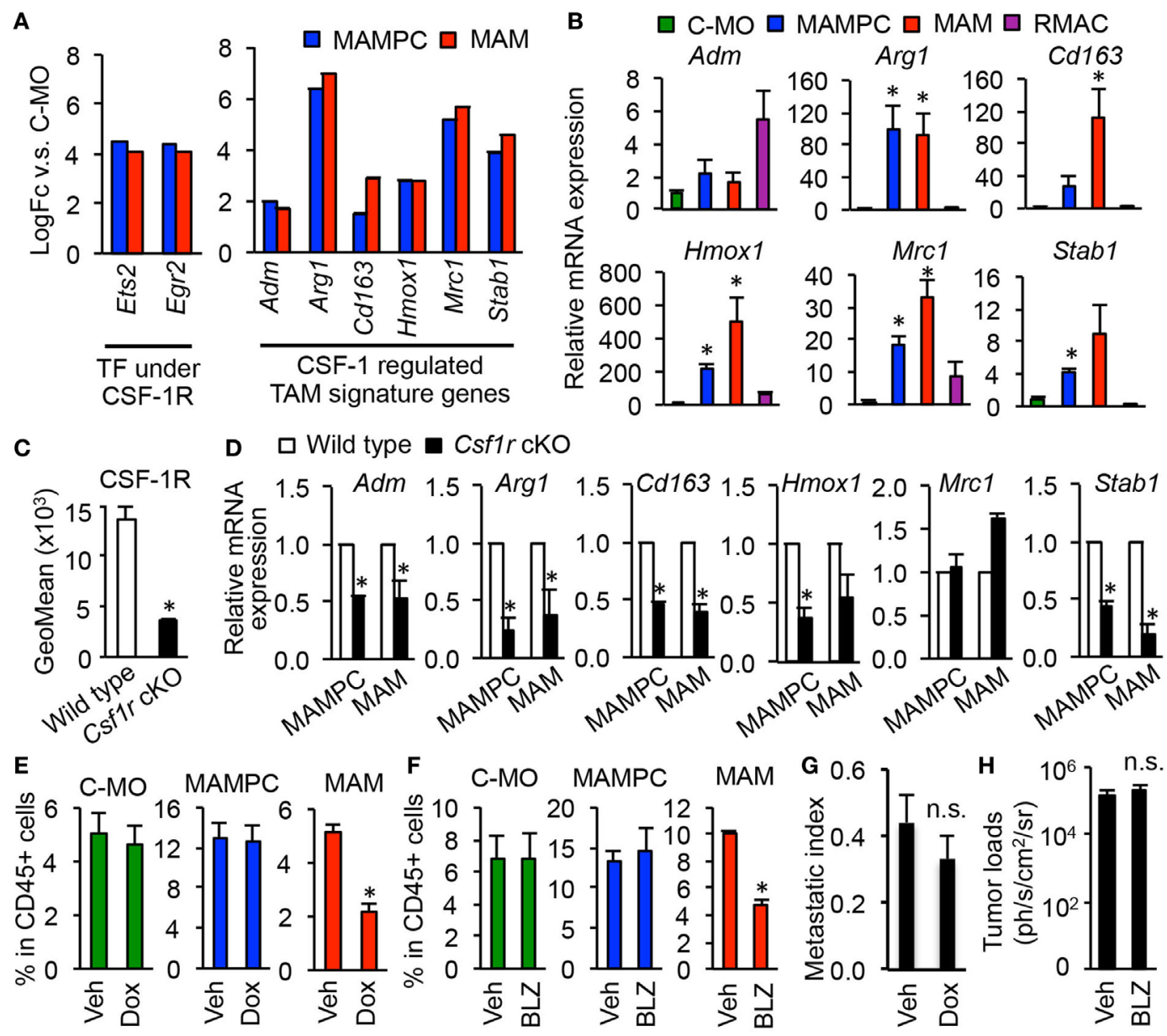

FIGURE 4 | Colony-stimulating factor 1 (CSF1) signaling is required for tumor-associated macrophage (TAM) signature gene expression in metastasis-associated macrophage precursor cells (MAMPCs) but is not essential for their accumulation in the metastatic site. (A) Fold-change of genes encoding transcription factors (TFs) and TAM-signature genes (15) under CSF1 receptor (CSF1R) control determined by microarray analyses in Figure $\mathbf{3}$. Graphs show genes whose expression was higher in MAMPCs and MAMs than classical monocytes (C-MOs) (logFC > 1, FDR < 0.05). Data on expression values are presented as mean \pm SEM. Note that the scale is exponential. (B) Relative mRNA expression assessed by quantitative RT-PCR in C-MOs (green), MAMPCs (blue), MAMs (red), and resident macrophages (RMACs) (Purple) ( $n=3$, two independent experiments). C-MOs were isolated from blood, and MAMPCs, MAMs, and RMACs were isolated from the metastatic lung of mice injected with E0771-LG cells. Data are mean \pm SEM, ${ }^{\star} P<0.05$ vs. C-MO. (C) Mean fluorescence intensity of CSF1R in circulating C-MOs from tumor-bearing C57BL/6 (wild type) and CSF1R conditional knockout (Csf1r cKO) mice treated with doxycycline from day 7 to day 14 after intravenous injection of E0771-LG cells ( $n=3$, two independent experiments). Data are mean \pm SEM, ${ }^{\star} P<0.01$. (D) Relative mRNA expression assessed by real time RT-PCR in MAMPCs and MAMs isolated from the metastatic lung of wild-type and Csf1r cKO mice that were treated as described above $(n=3$, two independent experiments). Data are mean \pm SEM, ${ }^{*} P<0.05$. (E) Relative numbers of C-MOs in the blood, and MAMPCs and MAMs in the metastatic lung of Csf1r cKO mice treated with doxycycline (Dox) or vehicle (Veh) as described above ( $n=3 /$ group, two independent experiments). Data are mean \pm SEM, ${ }^{\star} P<0.01$. (F) Relative numbers of C-MOs in the blood, and MAMPCs and MAMs in the metastatic lung of C57BL/6 mice treated with BLZ945, a selective CSF1R antagonist (BLZ) or Veh from day 7 to day 14 after intravenous injection of E0771-LG cells ( $n=3 /$ group, two independent experiments). Data are mean \pm SEM, * $P<0.01$. (G) Lung metastatic burden quantified as a metastasis index that is equal to total metastasis volume normalized by total lung volume. Csf1r cKO mice were treated with Dox or Veh from day 7 to day 14 after intravenous injection of E0771-LG cells ( $n=6$ /group, two independent experiments). Data are mean \pm SEM, ${ }^{\star} P<0.01$. (H) Lung metastatic burden quantified by bioluminescence imaging. C57BL/6 mice were treated with BLZ945 (BLZ) or Veh from day 7 to day 14 after intravenous injection of E0771-LG cells ( $n=3$ /group, two independent experiments). Data are mean \pm SEM, ${ }^{\star} P<0.01$.

fluorogenic caspase-3 substrate by microscopy (Figure 5A). As shown in Figure 5B, tumor cell apoptosis (i.e., number of red/ green double positive cells) was induced by preactivated CD8 ${ }^{+}$ $\mathrm{T}$ cells and enhanced in accordance with increased effector to target (E:T) ratios.

To test our hypothesis, we isolated MAMPCs, MAMs, and RMACs from the lung with metastatic E0771-LG tumors and cultured with splenic $\mathrm{CD} 8^{+} \mathrm{T}$ cells in the presence of anti-CD3/ CD28 activating antibodies. We then isolated the $\mathrm{CD}^{+} \mathrm{T}$ cells and evaluated their cytotoxicity against E0771-LG cells. The $\mathrm{CD}^{+} \mathrm{T}$ cells cocultured with MAMPCs or MAMs showed significantly lower cytotoxicity compared with the cells without the coculture (Figures $5 \mathrm{~A}, \mathbf{B}$ ). Although the $\mathrm{CD} 8^{+} \mathrm{T}$ cell cytotoxicity was also somewhat reduced by RMACs, their suppressive effect 

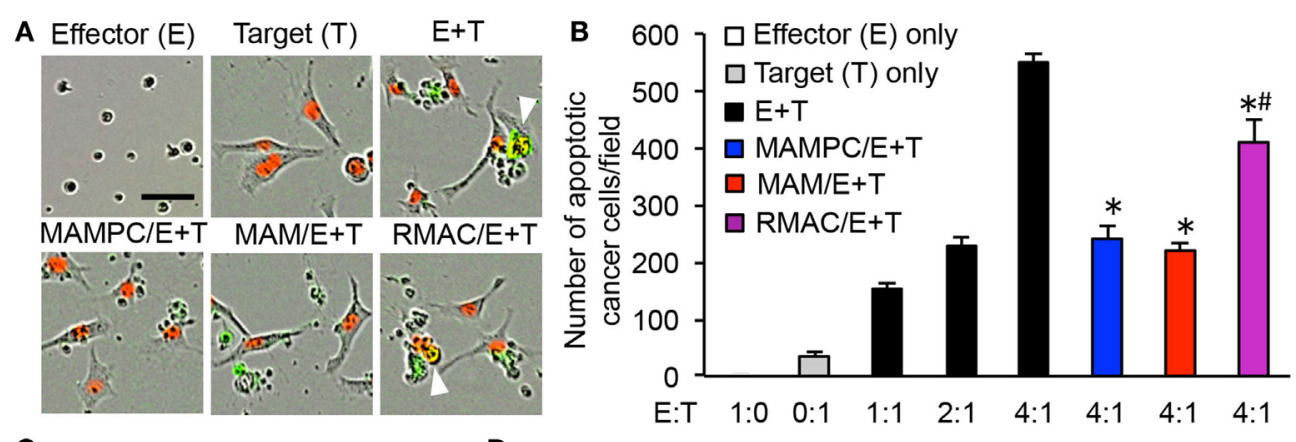

C

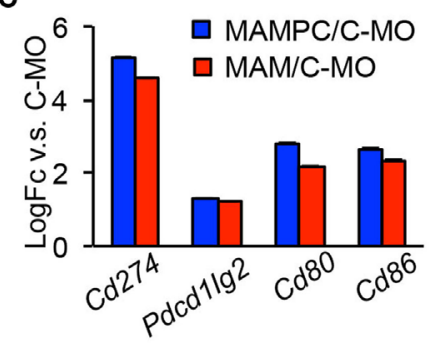

D

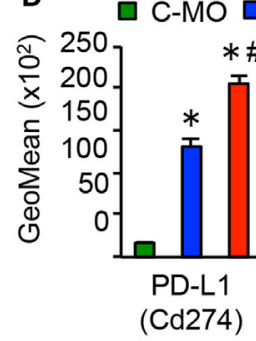

E
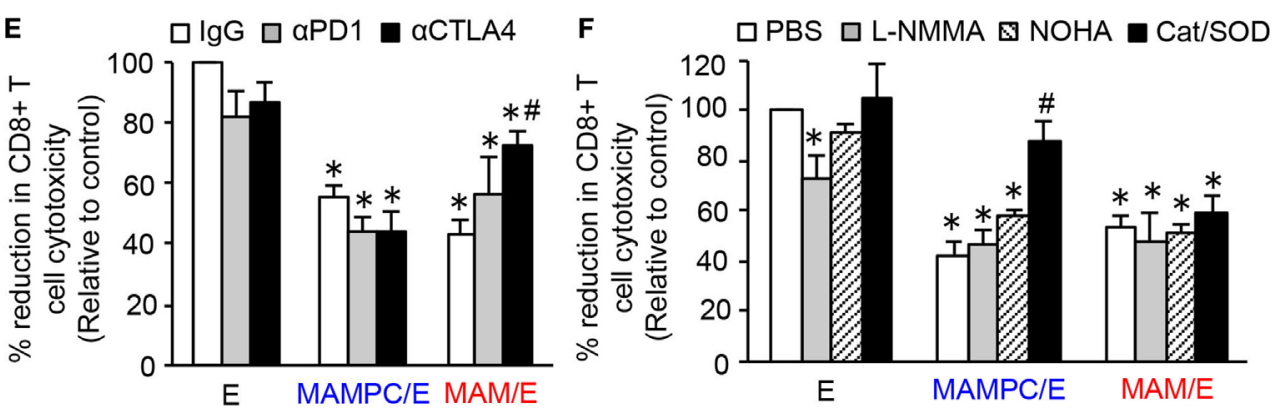

FIGURE 5 | Metastasis-associated macrophage (MAM) precursor cells (MAMPCs) suppress cytotoxicity of CD8 ${ }^{+} \mathrm{T}$ cells through a reactive oxygen species (ROS)-mediated mechanism. (A,B) Effects of myeloid cells on the CD8+ T cell-induced tumor cell apoptosis. Splenic CD8+ T cells from normal C57BL/6 mice were cultured with anti-CD3/CD28 antibodies (effector; E) in the absence or presence of MAMPCs, MAMs, or resident macrophages (RMACs) from the metastatic lung of E0771-LG-injected mice (MAMPC/E, MAM/E, RMAC/E, respectively). The preincubated T cells were then isolated and cultured with E0771-LG cells expressing red fluorescent protein in the nuclei (target; $T$ ) at the indicated $\mathrm{E}: \mathrm{T}$ ratio in the presence of green fluorogenic caspase-3 substrate. After $36 \mathrm{~h}$, the number of apoptotic cancer cells indicated by red/green double positive nuclei was counted. (A) Representative images of cells cultured with the caspase-3 substrate for $36 \mathrm{~h}$ (E:T $=4: 1)$. Scale bar; $50 \mu \mathrm{m}$, arrowhead; apoptotic cancer cell. (B) Number of apoptotic cancer cells cultured with preactivated CD8 ${ }^{+} \mathrm{T}$ cells $(n=3$, two independent experiments). Data are mean \pm SEM, ${ }^{\star} P<0.01$ vs. $E+T(4: 1),{ }^{\#} P<0.01$ vs. MAMPC/E $+T$. (C) Fold-change of genes encoding checkpoint $T$ cell receptor ligands in MAMPCs and MAMs compared with classical monocytes (C-MOs) determined by microarray analyses in Figure 3 (logFC > 1, FDR < 0.05). Data on expression values are presented as mean \pm SEM. Note that the scale is exponential. (D) Mean fluorescence intensity of checkpoint T cell receptor ligands assessed by flow cytometry in C-MOs, MAMPCs, and MAMs ( $n=3$, two independent experiments). Blood (for C-MOs) and lung digestion (for MAMPCs and MAMs) were prepared from E0771-LG-injected C57BL/6 mice at 14 days posttumor injection and stained with antibodies for indicated markers or isotype lgG. Data are mean \pm SEM, ${ }^{*} P<0.01$ vs. IM, ${ }^{*} P<0.01$ vs. MAMPC. (E) Effects of checkpoint inhibitors on the suppressive activity of MAMPCs and MAMs $(n=6$, two independent experiments). CD8 ${ }^{+} \mathrm{T}$ cells were cultured with anti-CD3/CD28 antibodies and neutralizing antibodies for PD1 or CTLA4, or isotype lgG in the absence (effector; E) or presence of MAMPCs (MAMPC/E) or MAMs (MAM/E). Cytotoxicity of the precultured CD8+ T cells against E0771-LG cells at 4:1 E/T ratio were assessed as described above. Data are mean \pm SEM that represent the ratio in number of apoptotic cancer cells relative to that induced by $\mathrm{CD}^{+} \mathrm{T}$ cells cultured with IgG in the absence of MAMPCs or MAMs (control). ${ }^{*} P<0.01$ vs. control, ${ }^{*} P<0.01$ vs. IgG. (F) Effects of inhibitors of nitric oxide or ROS production on the suppressive activity of MAMPCs and MAMs ( $n=6$, two independent experiments). CD8 ${ }^{+}$T cells were cultured with anti-CD3/CD28 antibodies and L-NMMA, nor-NOHA, catalase and superoxide dismutase (SOD) (Cat/SOD), or vehicle (-) in the absence (E) or presence of MAMPCs (MAMPC/E) or MAMs (MAM/E). Cytotoxicity of the precultured $\mathrm{CD}^{+} \mathrm{T}$ cells against E0771-LG cells at 4:1 E/T ratio were assessed as described above. Data are mean \pm SEM that represent the ratio of apoptotic cancer cells relative to that induced by $\mathrm{CD} 8+\mathrm{T}$ cells cultured with PBS in the absence of MAMPCs or MAMs (control). ${ }^{*} P<0.01$ vs. control, ${ }^{\sharp} P<0.01$ vs. PBS.

was significantly lower than MAMPCs or MAMs. Unfortunately we could not investigate suppressive effects of C-MOs due to the low number of cells collectible from the blood of tumor-bearing mice for this assay. Nevertheless and of importance, our data indicate that within the metastatic tissue MAMs and their immediate progenitors are immunosuppressive.
Our array data (Figure 5C) indicated that MAMPCs and MAMs compared with C-MOs expressed higher levels of mRNA coding PD-L1 (Cd274), PD-L2 (Pdcd1lg2), CD80, and CD86 that negatively regulate $\mathrm{CD} 8^{+} \mathrm{T}$ cell responses upon binding to checkpoint receptors, programmed cell death protein 1 (PD-1) and cytotoxic T-lymphocyte-associated protein 4 (CTLA4) (36). 
Flow cytometry confirmed that MAMPCs and MAMs expressed higher levels of PD-L1, PD-L2, and CD80 proteins compared with circulating C-MOs, whereas CD86 was expressed only MAMs (Figure 5D). We thus investigated their contributions to the $\mathrm{CD}^{+} \mathrm{T}$ cell suppression using antibodies against PD1 or CTLA4. Anti-CTLA4 blocking antibody partly but significantly increased the cytotoxicity of $\mathrm{CD}^{+} \mathrm{T}$ cell suppressed by MAMs whereas anti-PD1 antibody did not affect the suppressive activity of MAMs (Figure 5E), suggesting that CD80/CD86 expression on MAMs (Figure 5D) might have a role in the MAM-induced suppression. On the other hand, neither PD1 nor CTLA4 inhibition reversed the MAMPC-induced $\mathrm{CD}^{+} \mathrm{T}$ cell suppression (Figure 5E), suggesting that checkpoint receptors play a minor role in the suppressive mechanism of MAMPCs if any. We then investigated whether the MAMPC-induced suppression is mediated by arginase-1, inducible nitric oxide synthase (iNOS), and ROS that are key factors for MDSCs to exert immune suppressive activity (37). As shown in Figure 5F, combination of superoxide dismutase (SOD) and ROS-scavenging enzyme catalase significantly reversed the $\mathrm{CD} 8^{+} \mathrm{T}$ cell paralysis induced by MAMPCs, whereas this inhibition was not reversed by the iNOS inhibitor L-NMMA nor the arginase inhibitor NOHA. These results suggest that MAMPCs suppress CD8 ${ }^{+} \mathrm{T}$ cell cytotoxicity at least partly by a ROS-mediated but not by a nitric oxide (NO)-mediated mechanism. In contrast, these inhibitors had no influence in the MAM-mediated CD8 ${ }^{+} \mathrm{T}$ cell suppression (Figure 5F).

Taken together, this study identified a distinct population of MAM precursor in the metastatic sites that accumulate during the metastatic tumor growth by CSF1R independent mechanism, and suppress $\mathrm{CD}^{+} \mathrm{T}$ cell cytotoxicity by a ROS-mediated but checkpoint receptor-independent mechanism.

\section{DISCUSSION}

Myeloid cells such as macrophages, neutrophils, and MDSCs are known to accumulate in the tumor microenvironment and to actively promote the metastatic process (4). Using metastatic breast cancer models in mice, we have reported that MAMs, a distinct population of macrophages, abundantly accumulate in the tumor-challenged lung where they promote extravasation and survival of metastatic cancer cells (10). We have also identified that C-MOs preferentially migrate to the metastatic tumors and differentiate into MAMs (20). However, the fate and characteristics of the C-MOs after their migration into the metastatic site has not been elucidated.

Using a monocyte tracking method, we have identified here that circulating $\mathrm{C}-\mathrm{MOs}\left(\mathrm{CD} 11 \mathrm{~b}^{+} \mathrm{Ly} 6 \mathrm{C}^{+}\right)$differentiate into a distinguishable myeloid cell population characterized by being CD $11 b^{\text {high }}$ Ly6 $6 C^{\text {high }}$ immediately after migrating to the metastatic lung. Since the CD $11 \mathrm{~b}^{\text {high }} \mathrm{Ly} 6 \mathrm{C}^{\text {high }}$ cells shift over time into a gate of MAMs (CD11b $b^{\text {high }}$ Ly6 $\mathrm{C}^{\text {low }}$ ) in the metastatic site, these cells can be identified as MAMPCs. Although C-MOs differentiate to CD11b ${ }^{+}$Ly6C $C^{\text {low }}$ (NC-MOs) in the blood, these cells were distinct from the CD11b $\mathrm{b}^{\text {high }} \mathrm{Ly} 6 \mathrm{C}^{\text {low }}$ MAMs by their lower expression of CD11b, F4/80, and MHC-II. Since C-MOs preferentially migrate to the metastatic lung than NC-MOs (20), the majority of MAMs in the lung are differentiated from C-MOs through MAMPCs, although our data does not exclude a minor contribution of
NC-MOs recruited to the metastatic site or tissue-RMACs of embryonic origin as suggested by recent studies $(38,39)$.

Accumulation of the CD $11 b^{\text {high }} L y 6 C^{\text {high }}$ cells was found in the lung with metastatic mammary tumors developed by E0771-LG or Met-1 cells experimentally and by PyMT transgene spontaneously. Although the number of CD11b $b^{\text {high }}$ Ly6 $6 C^{\text {high }}$ cells in the spontaneous model (PyMT) was lower than that in the experimental model (E0771), it is probably because PyMT mice on $\mathrm{C} 57 \mathrm{BL} / 6$ background develop lower numbers and smaller tumors $\left(0.3 \pm 0.2 \mathrm{foci} / \mathrm{mm}^{2}\right.$ lung, $0.3 \pm 0.2 \mathrm{~mm}$ diameter $/$ foci $)$ compared with E0771-injected C57BL/ 6 mice $\left(1.0 \pm 0.3 \mathrm{foci} / \mathrm{mm}^{2}\right.$ lung, $0.5 \pm 0.1 \mathrm{~mm}$ diameter/foci, $P<0.01)$. Consistent with this interpretation, the number of the Ly $6 \mathrm{C}^{\text {high }}$ cells in the experimental model correlated with tumor load in the lung. These results suggest that accumulation of the CD $11 b^{\text {high }}$ Ly6 $6 C^{\text {high }}$ MAMPCs in the metastatic site is a common feature of breast cancer models in mice. Consistent with these data, a recent study has reported that $\mathrm{CD} 11 \mathrm{~b}{ }^{+} \mathrm{Ly} 6 \mathrm{C}^{\text {high }}$ cells are recruited to the lung with metastatic tumors developed by 4T1 mouse mammary tumor cells (40).

Metastasis-associated macrophage precursor cells are clearly distinguished from C-MOs or MAMs by their high CD11b and Ly6C expression as well as by their gene expression profile. Their low Ly6G expression excludes the possibility that they are neutrophils, as does their morphology. On the other hand, the phenotype of MAMPCs with CD $11 b^{\text {high }}$ Ly6 $6 C^{\text {high }}$ Ly $6 G^{-}$resembles that of a subpopulation of MDSC called M-MDSCs (33). A recent report has proposed three criteria to identify cells as MDSCs; a population of cells (i) expanded compared with normal conditions, (ii) have typical phenotype of MDSCs $\left(\mathrm{CD} 11 \mathrm{~b}^{+} \mathrm{Ly}_{6 \mathrm{C}} \mathrm{L}^{\mathrm{L}} \mathrm{L} 6 \mathrm{G}^{-}\right.$for M-MDSC in mice) and (iii) possesses immune suppressive activity (33). We have shown that the MAMPCs are characterized as $\mathrm{CD} 11 \mathrm{~b}^{+} \mathrm{Ly}_{6 \mathrm{C}} \mathrm{Ly}^{\mathrm{hi}} 6 \mathrm{G}^{-}$, expand in the lung with metastatic tumors compared with the normal lung, and suppress $\mathrm{CD}^{+}$ $\mathrm{T}$ cell cytotoxicity in vitro. Therefore, the MAMPCs accumulate in the metastatic lung of breast cancer models can be identified as M-MDSCs.

Monocytic MDSCs have been defined as myeloid cells that are distinct from mature myeloid cells such as macrophages and neutrophils, but are morphologically and phenotypically similar to monocytes (34). In our model, the majority of MAMPCs in the metastatic lung had a larger cytoplasm containing vacuoles, which is clearly distinct from typical monocyte morphology but similar to MAMs, suggesting that M-MDSCs in the metastatic sites (i.e., MAMPCs) are committed to macrophage lineage compared with circulating C-MOs. Consistent with these data, the gene expression profile of MAMPCs was closer to that of MAMs than C-MOs, and the majority of MAMPCs expressed high levels of mature macrophage markers such as CD14, CD36, CD64, and CD206. Compared with C-MOs, MAMPCs expressed higher levels of TAM signature genes (i.e., Arg1, Cdh1, Hmox1, Illr2, $M r c 1$, and Stab1) that were also highly expressed by MAMs, suggesting that differentiation of C-MOs to MAMPCs (M-MDSCs) is directed toward the tumor-promoting macrophages. Since circulating C-MOs expressed much lower levels of these macrophage markers compared with MAMPCs and only very minor population of C-MOs (6.5\%) showed the MAMPC-like morphology with cytoplasmic vacuoles, differentiation of C-MOs to M-MDSCs occurs mainly in the metastatic sites. Since these cells 
accumulate in the metastatic tissue, this suggests that the rate of C-MO recruitment by high CCL2 (20) and their differentiation into MAMPCs exceeds the rate of MAMPC differentiation into MAMs, although the monocyte tracking experiment indicates that they will all do so eventually.

It has been reported that $\mathrm{CD} 11 \mathrm{~b}^{+} \mathrm{Gr}-1^{+}$MDSCs transferred into the mice with $\mathrm{C} 3$ fibrosarcoma or EL4 lymphoma reduce their Gr1 (Ly6C/Ly6G) expression and express a macrophage marker F4/80 (41, 42). These results suggest that M-MDSCs can differentiate into TAMs in the tumor microenvironment, whereas the fate of M-MDSCs in the metastatic tumor microenvironment has not been fully identified. Our study shows direct evidence that the CD11 $b^{\text {high }}$ Ly6 $\mathrm{C}^{\text {high }} \mathrm{M}-\mathrm{MDSC}$ originate from C-MOs and differentiate into MAMs (CD11 $b^{\text {high }}$ Ly6 $\left.6 C^{\text {low }}\right)$ in the metastatic site. Consistent with our data, treatment of $4 \mathrm{~T} 1$ tumor-bearing mice with all trans retinoic acid reduces the number of $\mathrm{CD} 11 \mathrm{~b}^{+} \mathrm{Gr}-1^{+}$ cells and concomitantly increases the number of $\mathrm{CD}_{1} 1 \mathrm{~b}^{+} \mathrm{Gr}-$ $1^{-} \mathrm{F} 4 / 80^{+}$cells in the metastatic lung (43).

In this $4 \mathrm{~T} 1$ tumor model, both $\mathrm{Gr}-1^{+}$cells and F4/80+ cells from the metastatic lung have ability to suppress $\mathrm{T}$ cell proliferation and their cytokine secretion whereas the suppressive effects are stronger in $\mathrm{F} 4 / 80^{+}$cells than $\mathrm{Gr}-1^{+}$cells, suggesting that MAMs are more potent immune suppressors than MDSCs (43). In contrast, our data indicate that CD $11 b^{\text {high }}$ Ly6 $C^{\text {high }}$ cells (M-MDSCs/MAMPCs) and CD11 $\mathrm{b}^{\text {high }}$ Ly6C $\mathrm{C}^{\text {low }}$ cells (MAMs) suppress cytotoxicity of preactivated $\mathrm{CD}^{+} \mathrm{T}$ cells at comparable levels. This discrepancy can be explained by heterogeneity of MDSCs in the former experiment, i.e., Gr- $1^{+}$cells include not only M-MDSCs $\left(\mathrm{CD} 11 \mathrm{~b}^{+} \mathrm{Ly} 6 \mathrm{C}^{\text {high }} \mathrm{Ly}_{6 \mathrm{G}^{-}}\right.$) but also include less

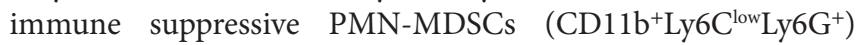
since anti-Gr-1 antibody recognizes both Ly6C and Ly6G (44). As anti-Ly6C antibody does not cross react with Ly6G, it is more specific to M-MDSCs. Consequently, our data suggest that both MAMs and their progenitor MAMPCs are potent immune suppressors in the metastatic tumors.

In our metastatic breast cancer model utilizing E0771-LG cells, suppression of $\mathrm{CD}^{+} \mathrm{T}$ cell cytotoxicity by MAMPC (M-MDSC) was reversed by a combination of catalase and SOD but not by L-NMMA, suggesting that M-MDSCs in the metastatic site of breast cancer use ROS rather than NO to suppress $\mathrm{T}$ cell functions. Consistent with these data, similar results were observed in $4 \mathrm{~T} 1$ metastatic breast cancer model, i.e., $\mathrm{T}$ cell suppression by $\mathrm{CD} 11 \mathrm{~b}^{+} \mathrm{Gr} 1^{+}$MDSCs from metastatic lung was restored by catalase but not by L-NMMA (43). On the other hand, M-MDSCs isolated from the ascites or spleen of EL4 lymphoma-injected mice were reported to suppress $\mathrm{T}$ cell functions largely by production of $\mathrm{NO}$ and/or reactive nitrogen species $(42,44,45)$. These results suggest that M-MDSCs might utilize different suppressive mechanisms in response to the tumor microenvironment that are determined by tumor types and location. Our results also suggest that MAMs and MAMPCs utilize different mechanism to suppress $\mathrm{CD}^{+} \mathrm{T}$ cell cytotoxicity, as inhibitors for ROS or NO production had no influence in the MAM-mediated $\mathrm{CD}^{+} \mathrm{T}$ cell suppression. Given the diversity and plasticity of suppressor myeloid cells, a combination of inhibitors might therefore be needed to block the immunosuppressive tumor microenvironment.
In a mouse model of pancreatic cancer, inhibition of CSF1R signaling suppresses TAMs accumulation and their immune suppressive functions, and thereby synergize with checkpointblockade immunotherapy (13). Given the effects of BLZ945 and anti-CTLA4 antibody on MAM functions in our model, the combination of CSF1R antagonist and checkpoint inhibitor may also be effective for metastatic breast cancer. On the other hand, our results suggest that MAMPCs, another immunosuppressive compartment in the metastatic site, might not be targeted by this strategy. Interestingly, it has suggested that accumulation of MDSCs requires two sets of signals that are largely mediated by tumor and tumor stromal cell-derived growth factors (e.g., GM-CSF, etc.) and proinflammatory cytokines (e.g., IL-6, etc.) (34). A recent study also shows that high mobility group box 1 (HMGB1) secreted from human breast cancer cells induces differentiation of monocytes into M-MDSCs and their survival (46, 47 ), suggesting that these cytokines will be potential therapeutic targets to prevent MAMPC accumulation and further improve immunotherapy effects metastatic breast cancer.

This study shows, to our knowledge for the first time, that MAMs are differentiated from a distinct population of precursor cells (MAMPCs) that phenotypically represent the cells originally described as M-MDSCs, and prevent T cell cytotoxicity at least in vitro. Characteristics of the MAMPCs identified in this study highlight the importance of further investigation of mechanisms behind their development in the metastatic site, which will lead to a novel and effective strategies to improve immunotherapy for metastatic breast cancer.

\section{ETHICS STATEMENT}

All procedures involving mice were conducted in accordance with licensed permission under the UK Animal Scientific Procedures Act (1986) (Home Office license number PPL 70/8065).

\section{AUTHOR CONTRIBUTIONS}

TK and JP designed the research. TK and DB performed the experiments and analyzed the data. TK, DS, and NC established and performed the in vitro $\mathrm{CD}^{+} \mathrm{T}$ cell cytotoxicity assay. TK and YK generated the microarray data. LC and SF analyzed microarray data. TK, LC, and JP analyzed all the data and wrote the manuscript.

\section{ACKNOWLEDGMENTS}

We thank Dr. E. Mihich for providing E0771 cells, Dr. S.J. Gendler for providing PyMT BL6 mice, and S. Johnston and W. Ramsay for technical support for FACS. This work was kindly backed by the COST Action BM1404 Mye-EUNITER (http://www.myeeuniter.eu). COST is supported by the EU Framework Program Horizon 2020.

\section{FUNDING}

This work was supported by grants from Department of Defense Congressionally Directed Medical Research Programs 
[DOD\#W81xWH-11-1-0703 (TK), USA], National Institutes of Health [RO1\#CA172451 and PO1\#CA100324 (JP), USA], the Wellcome Trust [101067/Z/13/Z (JP), 109657/Z/15/Z (TK), and 615KIT/J22738 (TK), UK], and the MRC [MR/N022556/1 (JP and TK), UK].

\section{REFERENCES}

1. Jemal A, Bray F, Center MM, Ferlay J, Ward E, Forman D. Global cancer statistics. CA Cancer J Clin (2011) 61:69-90. doi:10.3322/caac.20107

2. Steeg PS. Targeting metastasis. Nat Rev Cancer (2016) 16:201-18. doi:10.1038/ nrc. 2016.25

3. Tevaarwerk AJ, Gray RJ, Schneider BP, Smith ML, Wagner LI, Fetting JH, et al. Survival in patients with metastatic recurrent breast cancer after adjuvant chemotherapy: little evidence of improvement over the past 30 years. Cancer (2013) 119:1140-8. doi:10.1002/cncr.27819

4. Kitamura T, Qian B-Z, Pollard JW. Immune cell promotion of metastasis. Nat Rev Immunol (2015) 15:73-86. doi:10.1038/nri3789

5. Lin EY, Nguyen AV, Russell RG, Pollard JW. Colony-stimulating factor 1 promotes progression of mammary tumors to malignancy. J Exp Med (2001) 193:727-40. doi:10.1084/jem.193.6.727

6. Zhao X, Qu J, Sun Y, Wang J, Liu X, Wang F, et al. Prognostic significance of tumor-associated macrophages in breast cancer: a meta-analysis of the literature. Oncotarget (2017) 8:30576-86. doi:10.18632/oncotarget.15736

7. Wyckoff JB, Wang Y, Lin EY, Li JF, Goswami S, Stanley ER, et al. Direct visualization of macrophage-assisted tumor cell intravasation in mammary tumors. Cancer Res (2007) 67:2649-56. doi:10.1158/0008-5472.CAN-06-1823

8. Lin EY, Li JF, Gnatovskiy L, Deng Y, Zhu L, Grzesik DA, et al. Macrophages regulate the angiogenic switch in a mouse model of breast cancer. Cancer Res (2006) 66:11238-46. doi:10.1158/0008-5472.CAN-06-1278

9. Chen Q, Zhang XH, Massagué J. Macrophage binding to receptor VCAM-1 transmits survival signals in breast cancer cells that invade the lungs. Cancer Cell (2011) 20:538-49. doi:10.1016/j.ccr.2011.08.025

10. Qian B, Deng Y, Im JH, Muschel RJ, Zou Y, Li J, et al. A distinct macrophage population mediates metastatic breast cancer cell extravasation, establishment and growth. PLoS One (2009) 4:e6562. doi:10.1371/journal.pone.0006562

11. Noy R, Pollard JW. Tumor-associated macrophages: from mechanisms to therapy. Immunity (2014) 41:49-61. doi:10.1016/j.immuni.2014.06.010

12. Mantovani A, Marchesi F, Malesci A, Laghi L, Allavena P. Tumour-associated macrophages as treatment targets in oncology. Nat Rev Clin Oncol (2017) 14:399-416. doi:10.1038/nrclinonc.2016.217

13. Zhu Y, Knolhoff BL, Meyer MA, Nywening TM, West BL, Luo J, et al. CSF1/ CSF1R blockade reprograms tumor-infiltrating macrophages and improves response to T-cell checkpoint immunotherapy in pancreatic cancer models. Cancer Res (2014) 74:5057-69. doi:10.1158/0008-5472.CAN-13-3723

14. DeNardo DG, Brennan DJ, Rexhepaj E, Ruffell B, Shiao SL, Madden SF, et al. Leukocyte complexity predicts breast cancer survival and functionally regulates response to chemotherapy. Cancer Discov (2011) 1:54-67. doi:10.1158/2159-8274.CD-10-0028

15. Pyonteck SM, Akkari L, Schuhmacher AJ, Bowman RL, Sevenich L, Quail DF, et al. CSF-1R inhibition alters macrophage polarization and blocks glioma progression. Nat Med (2013) 19:1264-72. doi:10.1038/nm.3337

16. Ries $\mathrm{CH}$, Cannarile MA, Hoves S, Benz J, Wartha K, Runza V, et al. Targeting tumor-associated macrophages with anti-CSF-1R antibody reveals a strategy for cancer therapy. Cancer Cell (2014) 25:846-59. doi:10.1016/j.ccr. 2014.05.016

17. Qian B-Z, Pollard JW. Macrophage diversity enhances tumor progression and metastasis. Cell (2010) 141:39-51. doi:10.1016/j.cell.2010.03.014

18. Zaynagetdinov R, Sherrill TP, Kendall PL, Segal BH, Weller KP, Tighe RM, et al. Identification of myeloid cell subsets in murine lungs using flow cytometry. Am J Respir Cell Mol Biol (2013) 49:180-9. doi:10.1165/rcmb.2012-0366MA

19. Kopf M, Schneider C, Nobs SP. The development and function of lung-resident macrophages and dendritic cells. Nat Immunol (2015) 16:36-44. doi:10.1038/ ni.3052

\section{SUPPLEMENTARY MATERIAL}

The Supplementary Material for this article can be found online at http://www.frontiersin.org/articles/10.3389/fimmu.2017.02004/ full\#supplementary-material.

20. Qian B-Z, Li J, Zhang H, Kitamura T, Zhang J, Campion LR, et al. CCL2 recruits inflammatory monocytes to facilitate breast-tumour metastasis. Nature (2011) 475:222-5. doi:10.1038/nature10138

21. Kitamura T, Qian B-Z, Soong D, Cassetta L, Noy R, Sugano G, et al. CCL2-induced chemokine cascade promotes breast cancer metastasis by enhancing retention of metastasis-associated macrophages. J Exp Med (2015) 212:1043-59. doi:10.1084/jem.20141836

22. Gibbings SL, Thomas SM, Atif SM, McCubbrey AL, Desch AN, Danhorn T, et al. Three unique interstitial macrophages in the murine lung at steady state. Am J Respir Cell Mol Biol (2017) 57:66-76. doi:10.1165/rcmb.2016-0361OC

23. Sabatel C, Radermecker C, Fievez L, Paulissen G, Chakarov S, Fernandes C, et al. Exposure to bacterial CpG DNA protects from airway allergic inflammation by expanding regulatory lung interstitial macrophages. Immunity (2017) 46:457-73. doi:10.1016/j.immuni.2017.02.016

24. Ritland SR, Rowse GJ, Chang Y, Gendler SJ. Loss of heterozygosity analysis in primary mammary tumors and lung metastases of MMTV-MTAg and MMTV-neu transgenic mice. Cancer Res (1997) 57:3520-5.

25. Sasmono RT, Oceandy D, Pollard JW, Tong W, Pavli P, Wainwright BJ, et al. A macrophage colony-stimulating factor receptor-green fluorescent protein transgene is expressed throughout the mononuclear phagocyte system of the mouse. Blood (2003) 101:1155-63. doi:10.1182/blood-2002-02-0569

26. Li J, Chen K, Zhu L, Pollard JW. Conditional deletion of the colony stimulating factor-1 receptor (c-fms proto-oncogene) in mice. Genesis (2006) 44:328-35. doi:10.1002/dvg.20219

27. Borowsky AD, Namba R, Young LJ, Hunter KW, Hodgson JG, Tepper CG, et al. Syngeneic mouse mammary carcinoma cell lines: two closely related cell lines with divergent metastatic behavior. Clin Exp Metastasis (2005) 22:47-59. doi:10.1007/s10585-005-2908-5

28. Ginhoux F, Jung S. Monocytes and macrophages: developmental pathways and tissue homeostasis. Nat Rev Immunol (2014) 14:392-404. doi:10.1038/ nri3671

29. Hey YY, Tan JKH, O’Neill HC. Redefining myeloid cell subsets in murine spleen. Front Immunol (2016) 6:652. doi:10.3389/fimmu.2015.00652

30. Ley K, Pramod AB, Croft M, Ravichandran KS, Ting JP. How mouse macrophages sense what is going on. Front Immunol (2016) 7:204. doi:10.3389/ fimmu.2016.00204

31. Stanley ER, Chitu V. CSF-1 receptor signaling in myeloid cells. Cold Spring Harb Perspect Biol (2014) 6:a021857. doi:10.1101/cshperspect.a021857

32. Van Overmeire E, Stijlemans B, Heymann F, Keirsse J, Morias Y, Elkrim Y, et al. M-CSF and GM-CSF receptor signaling differentially regulate monocyte maturation and macrophage polarization in the tumor microenvironment. Cancer Res (2016) 76:35-42. doi:10.1158/0008-5472.CAN-15-0869

33. Bronte V, Brandau S, Chen SH, Colombo MP, Frey AB, Greten TF, et al. Recommendations for myeloid-derived suppressor cell nomenclature and characterization standards. Nat Commun (2016) 7:12150. doi:10.1038/ ncomms 12150

34. Marvel D, Gabrilovich DI. Myeloid-derived suppressor cells in the tumor microenvironment: expect the unexpected. J Clin Invest (2015) 125:3356-64. doi:10.1172/JCI80005

35. Ugel S, De Sanctis F, Mandruzzato S, Bronte V. Tumor-induced myeloid deviation: when myeloid-derived suppressor cells meet tumor-associated macrophages. J Clin Invest (2015) 125:3365-76. doi:10.1172/JCI80006

36. Buchbinder EI, Desai A. CTLA-4 and PD-1 pathways: similarities, differences, and implications of their inhibition. Am J Clin Oncol (2016) 39:98-106. doi:10.1097/COC.0000000000000239

37. Gabrilovich DI, Nagaraj S. Myeloid-derived suppressor cells as regulators of the immune system. Nat Rev Immunol (2009) 9:162-74. doi:10.1038/ nri2506 
38. Hanna RN, Cekic C, Sag D, Tacke R, Thomas GD, Nowyhed H, et al. Patrolling monocytes control tumor metastasis to the lung. Science (2015) 350:985-90. doi:10.1126/science.aac9407

39. Zhu Y, Herndon JM, Sojka DK, Kim K, Knolhoff BL, Zuo C, et al. Tissueresident macrophages in pancreatic ductal adenocarcinoma originate from embryonic hematopoiesis and promote tumor progression. Immunity (2017) 47:323-38. doi:10.1016/j.immuni.2017.07.014

40. Ouzounova M, Lee E, Piranlioglu R, El Andaloussi A, Kolhe R, Demirci MF, et al. Monocytic and granulocytic myeloid derived suppressor cells differentially regulate spatiotemporal tumour plasticity during metastatic cascade. Nat Commun (2017) 8:14979. doi:10.1038/ncomms14979

41. Kusmartsev S, Gabrilovich DI. STAT1 signaling regulates tumor-associated macrophage-mediated $\mathrm{T}$ cell deletion. JImmunol (2005) 174:4880-91. doi:10.4049/jimmunol.174.8.4880

42. Corzo CA, Condamine T, Lu L, Cotter MJ, Youn JI, Cheng P, et al. HIF-1 $\alpha$ regulates function and differentiation of myeloid-derived suppressor cells in the tumor microenvironment. J Exp Med (2010) 207:2439-53. doi:10.1084/ jem.20100587

43. Hamilton MJ, Bosiljcic M, Lepard NE, Halvorsen EC, Ho VW, Banáth JP, et al. Macrophages are more potent immune suppressors ex vivo than immature myeloid-derived suppressor cells induced by metastatic murine mammary carcinomas. J Immunol (2014) 192:512-22. doi:10.4049/jimmunol.1300096

44. Movahedi K, Guilliams M, Van den Bossche J, Van den Bergh R, Gysemans C, Beschin A, et al. Identification of discrete tumor-induced myeloid-derived suppressor cell subpopulations with distinct T cell-suppressive activity. Blood (2008) 111:4233-44. doi:10.1182/blood-2007-07-099226

45. Youn JI, Nagaraj S, Collazo M, Gabrilovich DI. Subsets of myeloid-derived suppressor cells in tumor-bearing mice. JImmunol (2008) 181:5791-802. doi:10.4049/jimmunol.181.8.5791

46. Parker KH, Horn LA, Ostrand-Rosenberg S. High-mobility group box protein 1 promotes the survival of myeloid-derived suppressor cells by inducing autophagy. J Leukoc Biol (2016) 100:463-70. doi:10.1189/jlb.3HI0715305R

47. Su Z, Ni P, She P, Liu Y, Richard SA, Xu W, et al. Bio-HMGB1 from breast cancer contributes to M-MDSC differentiation from bone marrow progenitor cells and facilitates conversion of monocytes into MDSC-like cells. Cancer Immunol Immunother (2017) 66:391-401. doi:10.1007/s00262-016-1942-2

Conflict of Interest Statement: The authors declare that the research was conducted in the absence of any commercial or financial relationships that could be construed as a potential conflict of interest.

Copyright (c) 2018 Kitamura, Doughty-Shenton, Cassetta, Fragkogianni, Brownlie, Kato, Carragher and Pollard. This is an open-access article distributed under the terms of the Creative Commons Attribution License (CC BY). The use, distribution or reproduction in other forums is permitted, provided the original author (s) or licensor are credited and that the original publication in this journal is cited, in accordance with accepted academic practice. No use, distribution or reproduction is permitted which does not comply with these terms. 